University of Tennessee Health Science Center

UTHSC Digital Commons

\title{
The Effects of Glucose Tolerance, Hypertension, and Race on Heart Rate Variability, QT Interval Duration, and Left Ventricular Hypertrophy in Overweight-Obese Adolescents
}

\author{
Shirleatha T. Lee \\ University of Tennessee Health Science Center
}

Follow this and additional works at: https://dc.uthsc.edu/dissertations

Part of the Nursing Commons

\footnotetext{
Recommended Citation

Lee, Shirleatha T. , "The Effects of Glucose Tolerance, Hypertension, and Race on Heart Rate Variability, QT Interval Duration, and Left Ventricular Hypertrophy in Overweight-Obese Adolescents" (2009). Theses and Dissertations (ETD). Paper 146. http://dx.doi.org/10.21007/etd.cghs.2009.0176.
}

This Dissertation is brought to you for free and open access by the College of Graduate Health Sciences at UTHSC Digital Commons. It has been accepted for inclusion in Theses and Dissertations (ETD) by an authorized administrator of UTHSC Digital Commons. For more information, please contact jwelch30@uthsc.edu. 


\title{
The Effects of Glucose Tolerance, Hypertension, and Race on Heart Rate Variability, QT Interval Duration, and Left Ventricular Hypertrophy in Overweight- Obese Adolescents
}

\begin{abstract}
The prevalence of childhood obesity has increased remarkably within the past ten years with black youth disproportionately affected. Childhood obesity is linked to cardiovascular risk. Purposes of this study were to explore relationships between cardiac autonomic risk factors of heart rate variability (HRV), QT corrected (QTC) Interval duration, and Cornell voltage measures for left ventricular hypertrophy (LVH) to body mass index (BMI), relative body mass index (RBMI), and blood pressure (BP) measures, and to examine the effects of impaired glucose tolerance (IGT), hypertension, and race on these cardiac autonomic risk factors in overweight-obese adolescents.
\end{abstract}

Methods: Overweight and obese adolescents $(N=128)$, ages $11-18$ years, $(60.2 \%$ black, $63.3 \%$ female $)$ were included in this secondary data analysis. During the original study BMI, resting BP, 12-lead electrocardiogram (ECG), and 24-hour Holter measures were obtained. Overweight was defined as BMI $\geq$ $85^{\text {th }}$ percentile on age-gender specific growth charts and obesity as ${ }^{3} 95^{\text {th }}$ percentile. Systolic or diastolic $\mathrm{BP}>90^{\text {th }}$ percentile for age, height, and sex was considered elevated BP. An oral glucose tolerance test (1 $\mathrm{g}$ of dextrose $/ \mathrm{kg}$ with a maximum of $75 \mathrm{~g}$ ) or mixed meal tolerance test [(Sustacal/Boost) $(6 \mathrm{kcal} / \mathrm{kg}$, body weight, max $360 \mathrm{kcal}$ )] was conducted with IGT defined as either a fasting blood glucose ${ }^{3} 100$ and < $126 \mathrm{mg} / \mathrm{dl}$ or 2-hr post-load glucose ${ }^{3} 140$ and $<200 \mathrm{mg} / \mathrm{dl}$ based on the American Diabetes Association criteria. Holter data were analyzed for HRV time and frequency domain measures of circadian fluctuation (SDNN) and parasympathetic function (high frequency; HF) using Multi-parameter Arrhythmia Review Station (MARS) PC Analysis and Editing system. QTc and Cornell voltage ( $\mathrm{S}_{\mathrm{v} 3}+\mathrm{R}_{\mathrm{aVL}}$ ) measurements for LVH were obtained from a 12-lead ECG.

Results: In the total sample, $28 \%$ had IGT, $34 \%$ had prolonged QTC, $51 \%$ met criteria for elevated BP, and none met Cornell criteria for LVH. BMI and RBMI did not correlate with HRV measures, QTc, or Cornell voltage. Systolic BP was modestly correlated to Cornell voltage $(r=0.231, p=0.009)$. No significant difference was noted between glucose tolerance groups for HRV (HF, $p=0.25$; SDNN, $p=0.108), Q T c(p=$ $0.59)$, or Cornell voltage $(p=0.33)$. However, the IGT group tended to have a higher frequency of elevated BP $(64 \%$ vs. $47 \%, \chi=3.047, p=0.08)$. There was no significant difference in HF $(p=0.31)$, SDNN $(p=$ $0.80)$, and QTc $(p=0.92)$ between BP groups. However, overweight-obese adolescents with elevated BP displayed significantly higher measures of Cornell voltage $(0.95 \mathrm{mV}$ vs. $0.76 \mathrm{mV}, p=0.004)$ than nonhypertensive peers. No significant difference was identified between blacks vs. whites for HF $(p=0.106)$, QTc $(p=0.599)$, or Cornell voltage $(p=0.965)$ measures, however black youth displayed significantly lower SDNN $(p<0.001)$. The prevalence of IGT was similar between racial groups $(28.57 \%$ vs. $27.45 \%, \chi=$ $0.01, p=0.890)$.

Conclusion: Obesity alone is an independent factor for cardiovascular risk. Screening for QTC and LVH using Cornell voltage measurements for LVH using 12-lead ECG is recommended in all overweight-obese youth. Further studies examining a more diverse weight group should be considered.

Document Type

Dissertation

Degree Name

Doctor of Philosophy (PhD) 


\section{Program}

Nursing

Research Advisor

Patricia A. Cowan, Ph.D.

\section{Keywords}

adolescents, heart rate variability, impaired glucose tolerance, left ventricular hypertrophy, obesity, QT

\section{Subject Categories}

Medicine and Health Sciences | Nursing 
The Effects of Glucose Tolerance, Hypertension, and Race on Heart Rate Variability, QT Interval Duration, and Left Ventricular Hypertrophy in Overweight-Obese Adolescents

\author{
A Dissertation \\ Presented for \\ The Graduate Studies Council \\ The University of Tennessee \\ Health Science Center
}

\author{
In Partial Fulfillment \\ Of the Requirements for the Degree \\ Doctor of Philosophy \\ From The University of Tennessee
}

By

Shirleatha T. Lee

May 2009 
Copyright (C) 2009 by Shirleatha T. Lee All rights reserved 


\section{DEDICATION}

This dissertation is dedicated to my husband, Timmothye E. Lee, for his unconditional love and support throughout this challenging endeavor. This dissertation is also dedicated to my children, Calysa and Tiana, and my parents, Harvey and Shirley Taylor, for their guidance and support throughout my life; they helped to make this dream a reality.

Philippians 4:13 has been a constant inspiration to me. 


\section{ACKNOWLEDGEMENTS}

I would like to thank God for watching over me during this endeavor, and express gratitude to Dr. Patricia Cowan, for expertly guiding and supporting me every step of the way. As an advisor and role model she is truly a skilled Nursing Scientist who believes in every student and shares her passion for research. I would also like to express appreciation to Dr. Pedro Velasquez for his significant contribution to my educational experience and to my committee members for their support and helpful guidance: Dr. Sharon Husch, Dr. Zoila Sanchez, Dr. Glenn Wetzel, and Dr. Mona Wicks.

I would also like to acknowledge Sigma Theta Tau International Beta Theta Chapter at-large for grant support of a pilot study to examine QT Interval measurements. 


\begin{abstract}
The prevalence of childhood obesity has increased remarkably within the past ten years with black youth disproportionately affected. Childhood obesity is linked to cardiovascular risk. Purposes of this study were to explore relationships between cardiac autonomic risk factors of heart rate variability (HRV), QT corrected (QTc) Interval duration, and Cornell voltage measures for left ventricular hypertrophy (LVH) to body mass index (BMI), relative body mass index (RBMI), and blood pressure (BP) measures, and to examine the effects of impaired glucose tolerance (IGT), hypertension, and race on these cardiac autonomic risk factors in overweight-obese adolescents.
\end{abstract}

Methods: Overweight and obese adolescents $(\mathrm{N}=128)$, ages $11-18$ years, $(60.2 \%$ black, $63.3 \%$ female) were included in this secondary data analysis. During the original study BMI, resting BP, 12-lead electrocardiogram (ECG), and 24-hour Holter measures were obtained. Overweight was defined as $\mathrm{BMI} \geq 85^{\text {th }}$ percentile on age-gender specific growth charts and obesity as $\geq 95^{\text {th }}$ percentile. Systolic or diastolic BP $\geq 90^{\text {th }}$ percentile for age, height, and sex was considered elevated BP. An oral glucose tolerance test (1g of dextrose $/ \mathrm{kg}$ with a maximum of $75 \mathrm{~g}$ ) or mixed meal tolerance test [(Sustacal/Boost) (6 kcal/kg, body weight, max $360 \mathrm{kcal}$ )] was conducted with IGT defined as either a fasting blood glucose $\geq 100$ and $<126 \mathrm{mg} / \mathrm{dl}$ or 2 -hr post-load glucose $\geq 140$ and $<200$ $\mathrm{mg} / \mathrm{dl}$ based on the American Diabetes Association criteria. Holter data were analyzed for HRV time and frequency domain measures of circadian fluctuation (SDNN) and parasympathetic function (high frequency; HF) using Multi-parameter Arrhythmia Review Station (MARS) PC Analysis and Editing system. QTc and Cornell voltage $\left(\mathrm{S}_{\mathrm{v} 3}+\right.$ $\mathrm{R}_{\mathrm{aVL}}$ ) measurements for $\mathrm{LVH}$ were obtained from a 12-lead ECG.

Results: In the total sample, 28\% had IGT, 34\% had prolonged QTc, 51\% met criteria for elevated BP, and none met Cornell criteria for LVH. BMI and RBMI did not correlate with HRV measures, QTc, or Cornell voltage. Systolic BP was modestly correlated to Cornell voltage $(\mathrm{r}=0.231, \mathrm{p}=0.009)$. No significant difference was noted between glucose tolerance groups for HRV $(\mathrm{HF}, \mathrm{p}=0.25$; SDNN, $\mathrm{p}=0.108)$, QTc $(\mathrm{p}=$ $0.59)$, or Cornell voltage $(\mathrm{p}=0.33)$. However, the IGT group tended to have a higher frequency of elevated BP $(64 \%$ vs. $47 \%, \chi=3.047, p=0.08)$. There was no significant difference in HF $(p=0.31)$, SDNN $(p=0.80)$, and QTc $(p=0.92)$ between BP groups. However, overweight-obese adolescents with elevated BP displayed significantly higher measures of Cornell voltage $(0.95 \mathrm{mV}$ vs. $0.76 \mathrm{mV}, \mathrm{p}=0.004)$ than non-hypertensive peers. No significant difference was identified between blacks vs. whites for HF ( $\mathrm{p}=$ $0.106)$, QTc $(p=0.599)$, or Cornell voltage $(p=0.965)$ measures, however black youth displayed significantly lower SDNN $(\mathrm{p}<0.001)$. The prevalence of IGT was similar between racial groups $(28.57 \%$ vs. $27.45 \%, \chi=0.01, \mathrm{p}=0.890)$.

Conclusion: Obesity alone is an independent factor for cardiovascular risk. Screening for QTc and LVH using Cornell voltage measurements for LVH using 12-lead ECG is recommended in all overweight-obese youth. Further studies examining a more diverse weight group should be considered. 


\section{TABLE OF CONTENTS}

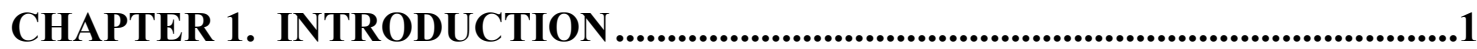

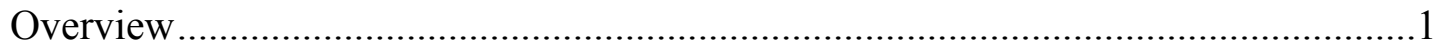

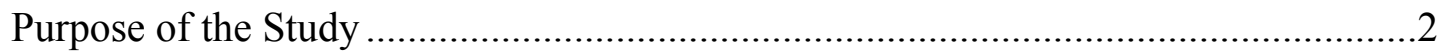

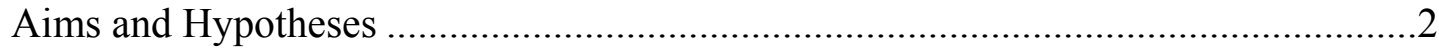

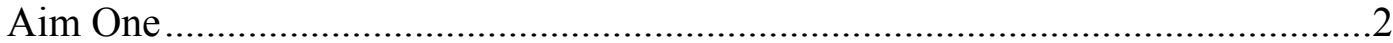

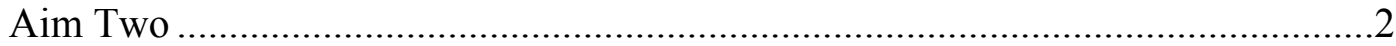

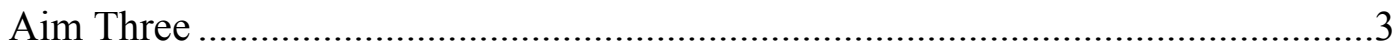

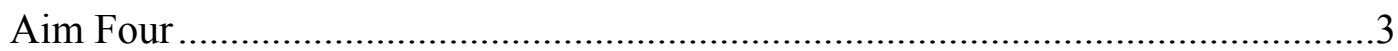

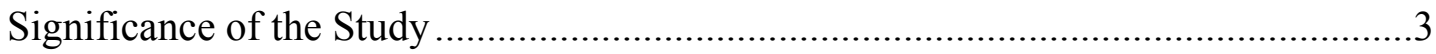

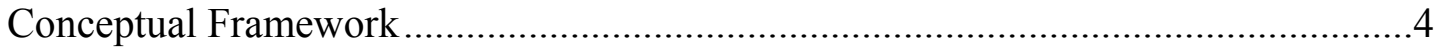

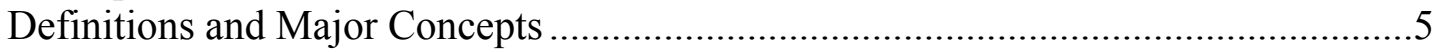

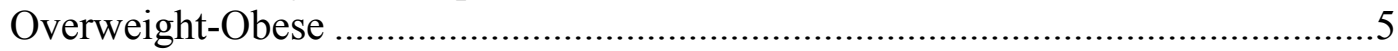

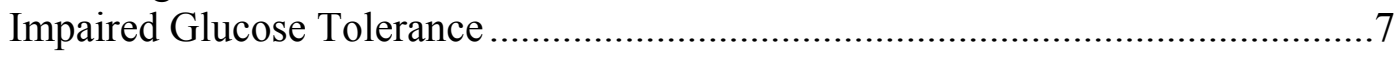

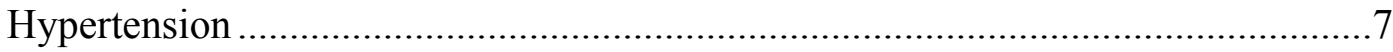

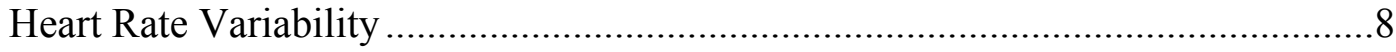

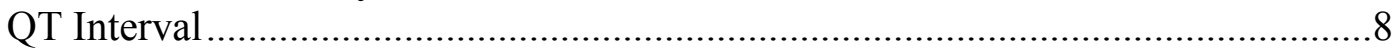

Left Ventricular Hypertrophy ................................................................... 8

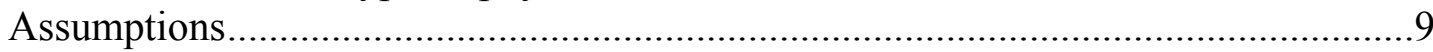

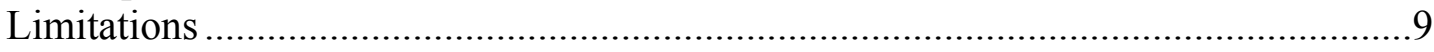

CHAPTER 2. REVIEW OF LITERATURE ...............................................11

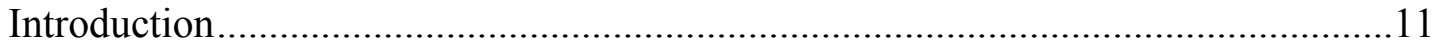

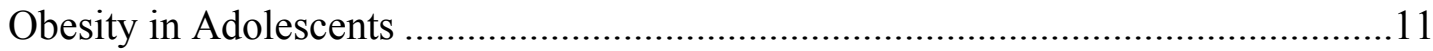

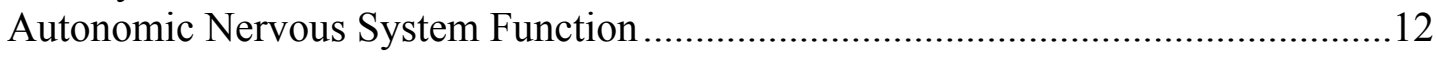

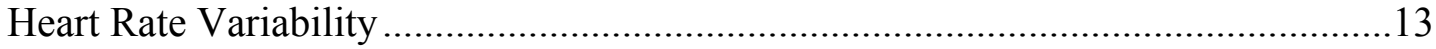

Heart Rate Variability: Age and Gender Effects ..............................................13

Heart Rate Variability: Racial Differences in Children ..........................................14

Heart Rate Variability and Childhood Obesity ..................................................14

Summary of Studies Examining Heart Rate Variability .....................................16

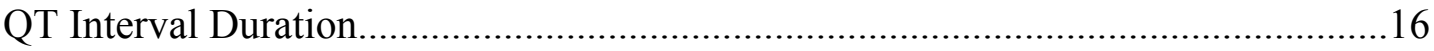

QT Interval Duration: Age and Gender Effects ...............................................17

QT Interval Duration: Racial Differences in Children.........................................17

QT Interval Duration and Childhood Obesity....................................................18

QT Interval Duration and Heart Rate Variability ............................................18

Summary of Studies Examining QT Interval Duration .................................... 18

Left Ventricular Hypertrophy ...............................................................................19

Left Ventricular Hypertrophy and 12-Lead Electrocardiogram Criteria ................19

Left Ventricular Hypertrophy: Age and Gender Effects....................................20

Left Ventricular Hypertrophy: Racial Differences in Children ...........................20

Left Ventricular Hypertrophy and Childhood Obesity .......................................20

Left Ventricular Hypertrophy/Hypertension and Heart Rate Variability ...............21

Left Ventricular Hypertrophy/Hypertension and QT Interval Duration................21

Summary of Studies Examining Left Ventricular Hypertrophy ..........................22 
Impaired Glucose Tolerance in Overweight-Obese Youth...................................22

Glucose Intolerance and Autonomic Dysfunction ..............................................23

Glucose Intolerance, Obesity, and Heart Rate Variability .................................23

Glucose Intolerance, Obesity, and QT Interval Duration ...................................25

Glucose Intolerance, Obesity, and Left Ventricular Hypertrophy .........................25

Summary of Glucose Intolerance, Autonomic Dysfunction, and Obesity.............25

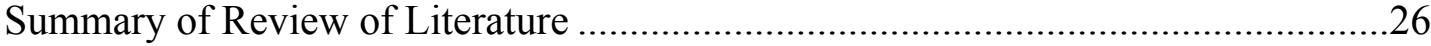

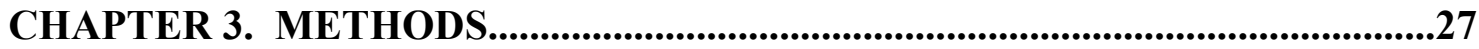

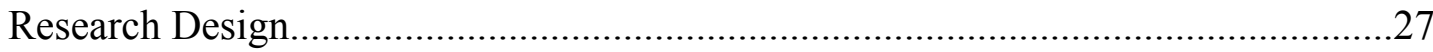

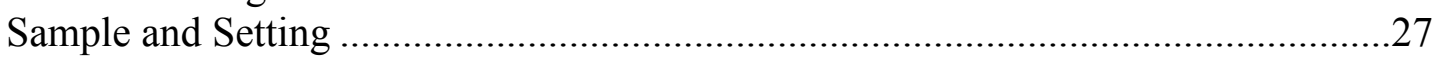

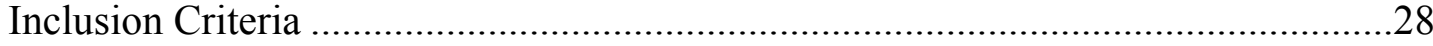

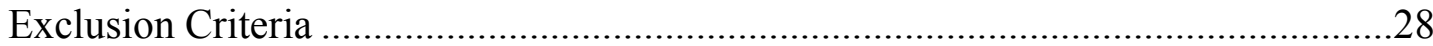

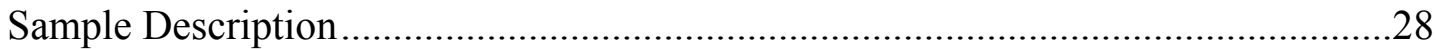

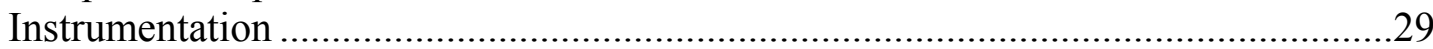

Body Mass Index and Relative Body Mass Index .............................................29

Oral Glucose and Mixed Meal Tolerance Test .................................................29

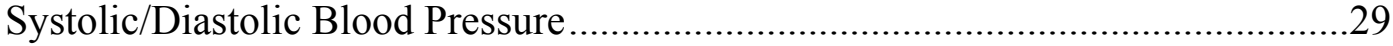

Ambulatory Electrocardiogram Analysis and Editing .....................................30

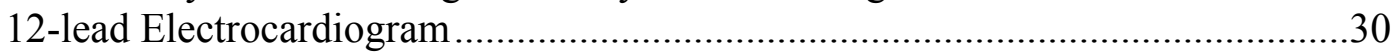

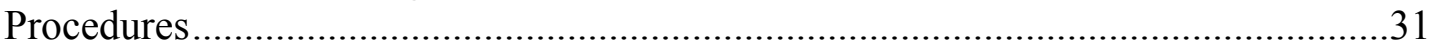

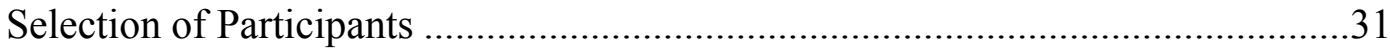

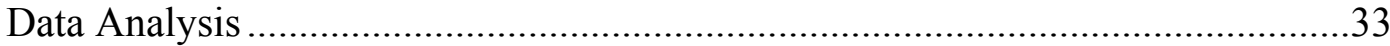

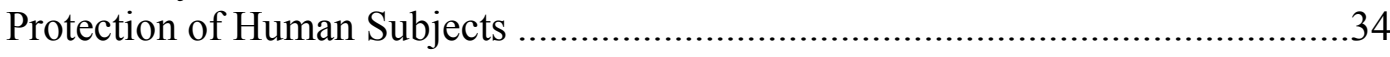

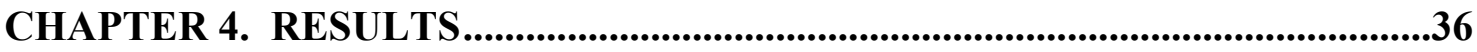

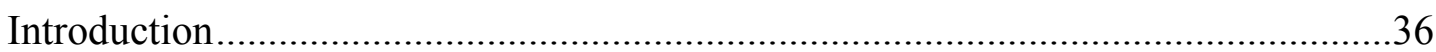

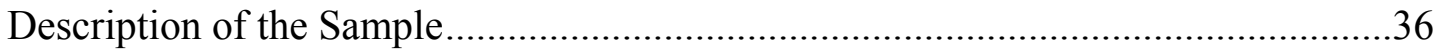

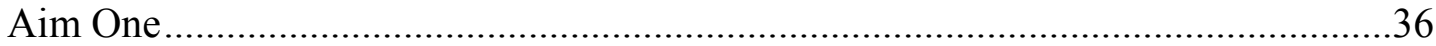

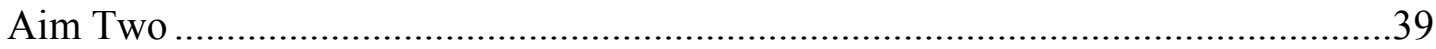

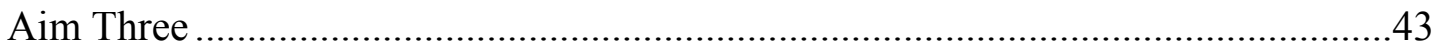

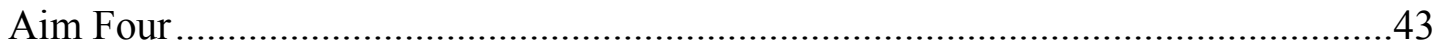

CHAPTER 5. DISCUSSION, IMPLICATIONS, AND CONCLUSIONS ............48

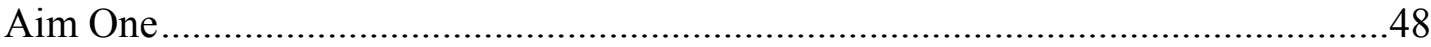

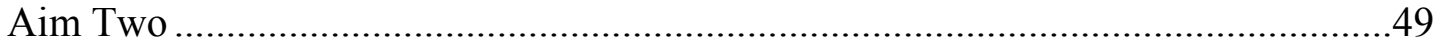

Aim Three ..................................................................................................... 50

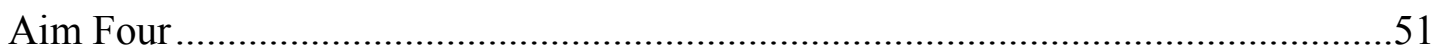

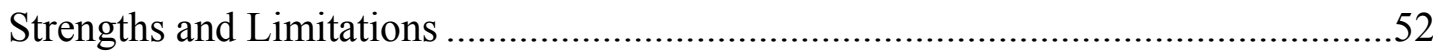

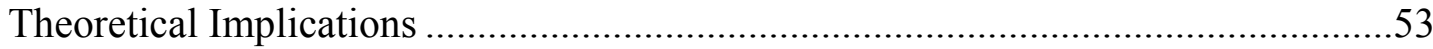

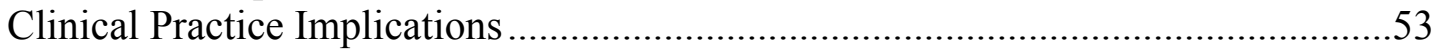

Recommendations for Future Research .............................................................5

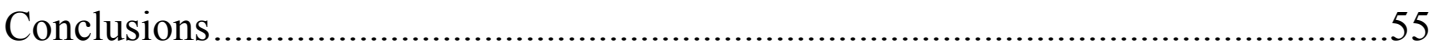




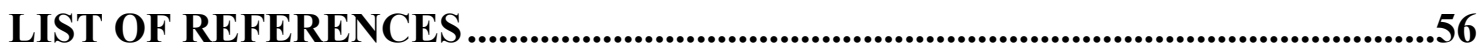

VITA 


\section{LIST OF TABLES}

Table 3-1. Variables and Measurements. ............................................................. 32

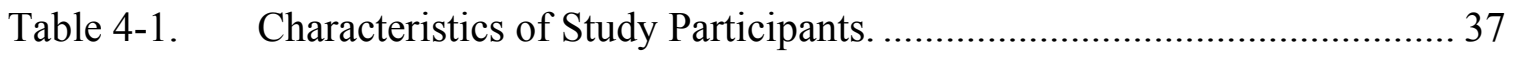

Table 4-2. Cardiac Risks in Overweight-Obese Adolescents. ................................. 38

Table 4-3. Correlations between Cardiac Risks in Overweight-Obese Adolescents. 40

Table 4-4. Characteristics of Study Participants Based on Glucose Status............... 41

Table 4-5. Cardiac Risks in Study Participants Based on Glucose Status. ............... 42

Table 4-6. Characteristics of Study Participants Based on Blood Pressure Status. ... 44

Table 4-7. Cardiac Risks in Study Participants Based on Blood Pressure Status..... 45

Table 4-8. Characteristics of Study Participants Based on Race. ............................ 46

Table 4-9. Cardiac Risks in Study Participants Based on Race. ............................... 47 


\section{LIST OF ABBREVIATIONS}

ANS.

Autonomic Nervous System

BMI Body Mass Index

$\mathrm{BP}$ Blood Pressure

CVD Cardiovascular Disease

DBP Diastolic Blood Pressure EKG Electrocardiogram

HF .High Frequency

HRV Heart Rate Variability

HTN Hypertension

IGT Impaired Glucose Tolerance LF Low Frequency

LVH Left Ventricular Hypertrophy MMTT Mixed Meal Tolerance Test

NGT . Normal Glucose Tolerance

OGTT Oral Glucose Tolerance Test

QT .Beginning of the QRS Complex to End Deflection of the T Wave

RBMI Relative Body Mass Index SBP Systolic Blood Pressure SDNN Standard Deviation of all Normal R-R Intervals T2DM Type 2 Diabetes Mellitus 


\section{CHAPTER 1. INTRODUCTION}

\section{Overview}

Healthy People 2010 identified obesity as a health care priority (Healthy People 2010, 2004). Childhood obesity has reached epidemic proportions in the United States; $25 \%$ of children are overweight and $11 \%$ obese (Dehghan, Akhtar-Danesh, \& Merchant, 2005). Disparities among racial groups for obesity exist, and non-Hispanic black male and female youth experienced the largest increase in prevalence of obesity between 2003 and 2006 (Centers for Disease Control, 2009). Physical and psychological health is adversely impacted by excess weight during adolescence (Dehghan et al., 2005). Obesity is a risk factor for a myriad of chronic diseases, including cardiovascular disease (CVD) and type 2 diabetes mellitus (T2DM) (Goran, Ball, \& Cruz, 2003) with manifestations of these diseases becoming more prevalent in obese adolescents (Goran et al., 2003). It has been suggested that childhood obesity accounts for up to $45 \%$ of all newly diagnosed cases of pediatric T2DM (Singhal, Schwenk, \& Kumar, 2007). Research suggests the development of T2DM in overweight-obese adolescents is similar to adults but with faster progression from impaired glucose tolerance (pre-diabetes) to overt disease (Cruz, Shaibi, Weigensberg, Spruijt-Metz, Ball, \& Goran, 2005), and impaired glucose tolerance (IGT) has increased among obese children (Cruz et al., 2005; Ryan, 2005).

While it is well documented that diabetes causes cardiac autonomic neuropathy, (Carnethon, Prineas, Temprosa, Zhang, Uwaifo, \& Molitch, 2006; Pappachan, Sebastian, Bino, Jayaprakash, Vijayakumar, Sujathan, et al., 2008; Perciaccante, Fiorentini, Paris, Serra, \& Tubani, 2006; Scott \& Kench, 2004; Valensi, Paries, \& Attali, 2003) there is a paucity of information on the effect of glucose intolerance on autonomic function in overweight and obese adolescents. Adiposity is linked to impaired cardiac autonomic function, which may result from the release of vasoactive substances from adipocytes that modulate sympathetic-parasympathetic balance. The literature supports the linkage between obesity and diminished parasympathetic measures of heart rate variability (HRV) in youth (Rabbia, Silke, Conterno, Grosso, De Vito, Rabbone, et al., 2003), however it is unclear whether adiposity in combination with IGT produces an increased incidence of cardiac alterations that may lead to sudden cardiac death (Webster \& Scott, 1997) in children. Cardiac alterations affected by autonomic dysfunction in overweightobese adolescents addressed within this study include: alterations in HRV, QTc (QT corrected) duration, and electrical voltage measurements for left ventricular hypertrophy $(\mathrm{LVH})$.

Heart rate variability changes are reflected in individuals with diabetes because of the tendency of those diagnosed with T2DM to develop autonomic neuropathy (McMillian, 2002). QTc Interval duration adjusts according to autonomic nervous system (ANS) activity (Haapalahti, Viitasalo, Perhonen, Makijarvi, Vaananen, Oikarinen, et al., 2006). Researchers have identified that there is a significant correlation between decreased HRV and the presence of LVH, with a decrease in HRV being shown to correlate with the extent of the hypertrophy present (Alter, Grimm, Vollrath, Czerny, \& Maisch, 2006). 
Despite the rapid increase in childhood obesity and associated health concerns, medical evaluation and treatment of childhood obesity have not consistently met the recommended standards (Plourde, 2006). Early diagnosis is essential to prevent the development of obesity-associated complications. Few research studies have been conducted examining HRV, QTc, and LVH collectively, and studies examining the concomitant impact of glucose tolerance, hypertension, and race on these variables in the overweight-obese adolescent population have not been reported. The current study, examined relationships between HRV, QTc duration, and electrical voltage measures for LVH to body mass index (BMI), relative body mass index (RBMI), and blood pressure measures. In addition, the effect of glucose tolerance, hypertension, and racial differences on HRV, QTc Interval duration, and electrical voltage measures for LVH in overweight-obese adolescents was examined.

\title{
Purpose of the Study
}

There is a paucity of research involving HRV, QTc, and electrical voltage measures for LVH in overweight-obese and pre-diabetic populations, and no published studies have examined these variables collectively in overweight-obese youth. Therefore, the purpose of this study was to explore relationships between HRV, QTc duration, and electrical voltage measures for LVH to BMI, RBMI, and blood pressure measures in overweight-obese adolescents. Additionally, this study examined the effects of glucose tolerance, hypertension, and race on HRV, QTc Interval duration, and electrical voltage measures for $\mathrm{LVH}$ in this population.

\section{Aims and Hypotheses}

The following specific research aims and hypotheses were addressed:

\begin{abstract}
Aim One
Examine the relationship of HRV, QTc Interval duration, and electrical voltage measures of LVH to BMI, RBMI, and systolic/diastolic blood pressure measures in overweight-obese adolescents.

Hypothesis: Higher BMI, RBMI, and increased systolic/diastolic blood pressure measures will be associated with lower HRV, more prolonged QTc duration, and higher measures of electrical voltage for $\mathrm{LVH}$.
\end{abstract}

\begin{abstract}
Aim Two
Compare HRV, QTc Interval duration, and electrical voltage measures for LVH in overweight-obese adolescents with and without IGT.
\end{abstract}


Hypothesis: Overweight-obese adolescents with IGT will exhibit lower HRV measures, more prolonged QTc duration, and higher electrical voltage measures for LVH compared to overweight-obese adolescents with normal glucose tolerance.

\begin{abstract}
Aim Three
Compare HRV, QTc Interval duration, and electrical voltage measures for LVH in overweight-obese adolescents with and without elevated blood pressure.

Hypothesis: Overweight-obese adolescents with elevated blood pressure will exhibit lower HRV measures, more prolonged QTc duration, and higher electrical voltage measures for LVH compared to overweight-obese adolescents without elevated blood pressure.
\end{abstract}

\begin{abstract}
Aim Four
Compare HRV, QTc Interval, and electrical voltage measures for LVH in black and white overweight-obese adolescents.

Hypothesis: Black overweight-obese adolescents will display lower HRV, more prolonged QTc duration, and higher electrical voltage measures for LVH than their white peers.
\end{abstract}

\title{
Significance of the Study
}

Increased adiposity has been linked to impaired autonomic dysfunction (Rabbia et al., 2003), and the ANS either directly or indirectly influences glucose tolerance, blood pressure, HRV, QTc Interval duration, and LVH.

In individuals with decreased HRV, increases in sympathetic activity have been shown to increase ventricular arrhythmias (Reed, Robertson, \& Addison, 2005). In conditions where there is increased sympathetic activity and reduced parasympathetic activity, these are associated in increases in ventricular workload and myocardial oxygen demand (Soares, Moreno, Cravo, \& Nobrega, 2005). This situation increases the occurrence of ischemia and alters ionic currents throughout the myocardial cellular membrane, leading to electrical instability (Soares et al., 2005). This electrical instability can lead to life threatening arrhythmias resulting in sudden cardiac death (Soares et al., 2005).

A defect in the ion channels located within the heart may cause a delay in ventricular repolarization (QT syndrome, 2005; Texas Heart Institute, 2007) that is characterized by prolongation of the QT Interval (Toivonen, 2002). Torsades de Pointes may follow (Antzelevitch, 2005; Lanjewar, Pathak, \& Lokhandwala, 2004; QT 
syndrome, 2005; Texas Heart Institute, 2007; Toivonen, 2002), and result in sudden cardiac death (Lanjewar et al., 2004; QT syndrome, 2005).

Fibrosis potentially causes arrhythmias when LVH is present (Kahan, \& Bergfeldt, 2005). Fibers in the enlarged heart muscle become thick and short and relaxation is decreased, this results in stiff heart muscle that is less able to meet the body's demands (Family Blood Pressure Program, 2008). The change in the myocardium makes it less effective in generating and conducting electrical current throughout the heart muscle (Corrado, Bacharova, Antzelvitch, \& Kanters, 2007). This conduction defect starts early in LVH and progresses (Corrado et al., 2007). Defects in conduction can lead to arrhythmias, particularly Torsades de pointes, which may result in sudden cardiac death (Kahan \& Bergfeldt, 2005).

Faulkner, Quinn, Rimmer, and Rich (2005) noted that HRV is decreased in healthy black youth compared to whites. Limited research on QTc Interval and race has been published (Science Blog, 2002) and no studies were identified that examined QTc Interval duration in overweight-obese adolescents in regards to racial differences. Blacks also have a greater tendency to develop LVH than white peers (Drazner, 2004).

The knowledge obtained from this study contributes significantly to patients and healthcare by determining associations between HRV, QTc duration, and electrical voltage for LVH in relation to glucose tolerance, blood pressure status, and/or race in overweight-obese adolescents. The information obtained enhances general knowledge for these variables and their relationship to ANS function in overweight-obese adolescents. Clinically, results from this study may suggest additional risk stratification is warranted in adolescents and identify whether overweight-obesity with regards to concomitant glucose intolerance, hypertension, or race alone adversely affect HRV, QTc Interval duration, and/or electrical voltage measures for $\mathrm{LVH}$.

\section{Conceptual Framework}

The developed conceptual framework of this study was centered on ANS function, obesity, and the interrelated variables: IGT, hypertension, HRV, QTc Interval duration, and LVH. Obesity may result in autonomic dysfunction and blacks in comparison to whites have a disproportionately higher prevalence of being overweight (United States Department of Health and Human Services, 2009). Autonomic nervous system function may influence HRV (Bilcheck \& Berger, 2006), QTc duration (Viitasalo, Karjalainen, Makijarvi, \& Toivonen, 1998), and hypertension (Pal, Pal, Nanda, Amundharaj, \& Karthik, 2009), a risk factor for LVH (Sekine, Izumi, Yamagami, \& Kagamimori, 2001). Independent variables glucose tolerance and hypertension are also directly affected by the ANS. Sympathetic nervous system stimulation that occurs when obesity is present has been identified to have a significant impact on overall patient outcomes. The tendency to develop autonomic neuropathy in diabetes is reflected through changes in HRV (McMillian, 2002). Autonomic dysfunction can also potentially result in further increases in blood pressure due to the control of the ANS on blood 
vessels leading to a hypertensive state, contributing to the occurrence of LVH. Increased sympathetic stimulation associated with decreases in insulin secretion is also associated with the occurrence of arrhythmias in people with prolonged QTc Interval duration (Viitasalo et al., 1998). Although the exact relationship between increased sympathetic function and obesity has not been identified, researchers have hypothesized that a significant relationship does exist (Sekine et al., 2001). The conceptual model hypothesizes that hyperglycemia occurring with IGT may impact autonomic function even prior to the development of T2DM, and decreased HRV, QT prolongation, and the development of hypertension a common cause for LVH may follow, resulting in an increased risk for arrhythmias and sudden cardiac death.

Each of the three variables, decreased HRV (Reed et al., 2005), prolonged QTc Interval (QT syndrome, 2005), and LVH (Kahan \& Bergfeldt, 2005), may lead to the risk of sudden cardiac death. In individuals with decreased HRV, increases in sympathetic activity have been shown to increase ventricular arrhythmias (Reed et al., 2005). In conditions when there is increased sympathetic activity and reduced parasympathetic activity, there is increased ventricular workload and increased myocardial oxygen demand (Soares et al., 2005). This increases the occurrence of ischemia and alters ionic currents throughout the myocardial cellular membrane, leading to electrical instability (Soares et al., 2005). This electrical instability can lead to life- threatening arrhythmias resulting in sudden cardiac death (Soares et al., 2005).

Prolonged QT Interval is representative of a delay in ventricular repolarization (Toivonen, 2002) caused by a defect in the heart muscle cell structures called ion channels (QT syndrome, 2005; Texas Heart Institute, 2007). The delay in ventricular repolarization predisposes the heart to arrhythmias, with the most commonly caused arrhythmia being Torsades de Pointes (Antzelevitch, 2005; Lanjewar et al., 2004; QT syndrome, 2005; Texas Heart Institute, 2007; Toivonen, 2002), which may result in sudden cardiac death (Lanjewar et al., 2004; QT syndrome, 2005).

The change in the myocardium when LVH is present makes it less effective in generating and conducting electrical impulses throughout the heart muscle (Corrado et al., 2007). This conduction defect starts early in LVH and progresses (Corrado et al., 2007). The defects in conduction can lead to arrhythmias, particularly Torsades de Pointes, which may also lead to sudden cardiac death (Kahan \& Bergfeldt, 2005). See Figure 1-1.

\section{Definitions and Major Concepts}

\section{Overweight-Obese}

Overweight is defined in adolescents as a BMI [(weight $(\mathrm{kg}) /$ height $\left.^{2}\left(\mathrm{~m}^{2}\right)\right] \geq$ $85^{\text {th }}$ percentile for age and gender, while obesity equates to a BMI $\geq 95^{\text {th }}$ percentile by 


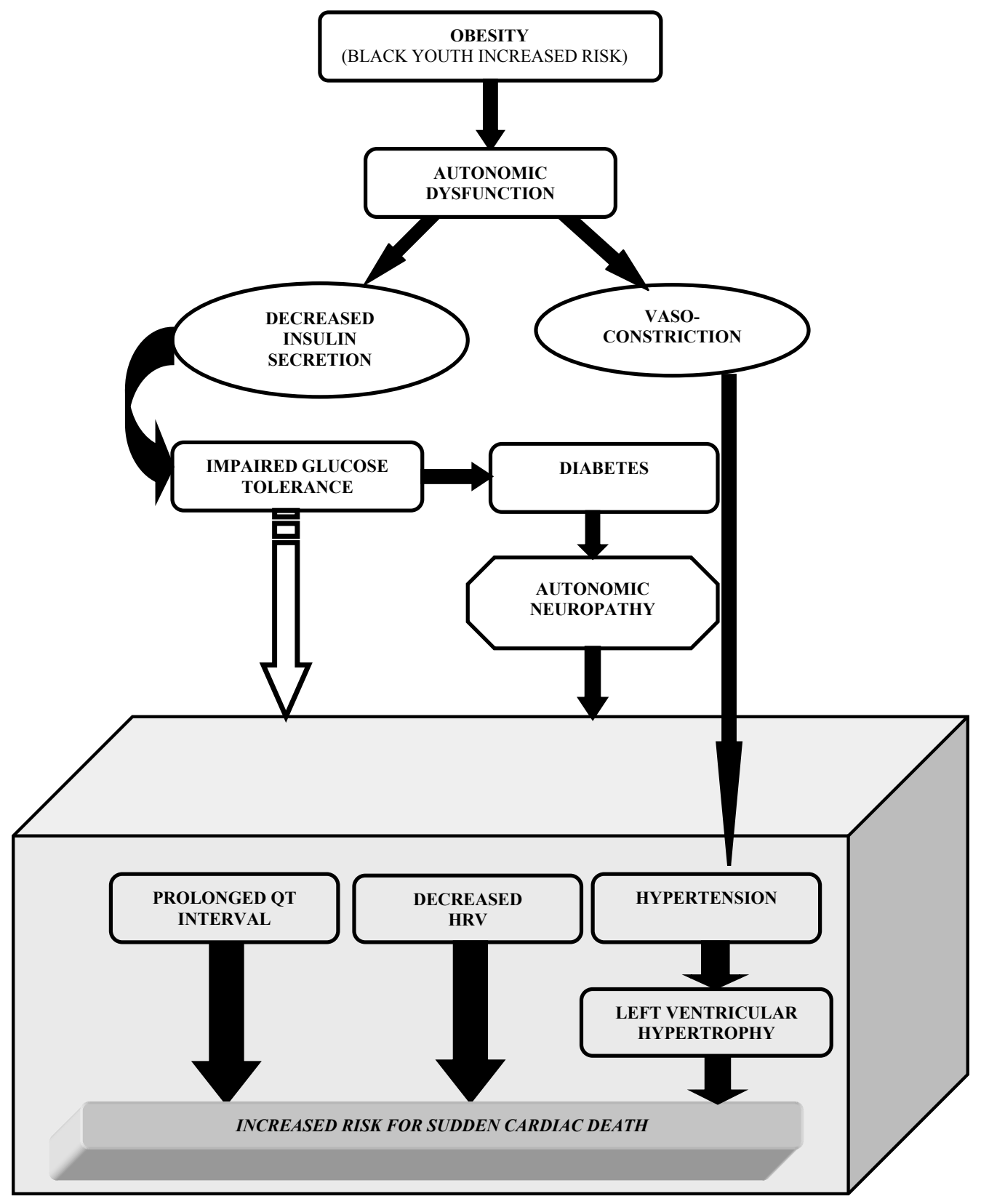

Figure 1-1. Conceptual Framework of Obesity and Cardiac Risks. 
age and gender percentile distributions (O’Brien, Nader, Houts, Bradley, Friedman, Belsky, et al., 2007).

According to the Centers for Disease Control (2008), BMI is a dependable calculation derived from an adolescent's height and weight to indicate body fatness. Dual energy x-ray absorptiometry (DXA) and underwater weighing are direct measures of body fatness but are often expensive and time consuming. (Centers for Disease Control, 2008). Although BMI does not directly measure body fat, reports have indicated a significant correlation of BMI to DXA and underwater weighing, and it is a rapid and inexpensive method of identifying body fatness in adolescents (Centers for Disease Control, 2008). Relative body mass index (RBMI) is useful in examining children of various ages and sexes for severity of obesity (Wang, Ge, \& Popkin, 2000). It is a meaningful, continuous variable and represents the BMI divided by a standard BMI for age and sex and should remain relatively unchanged as age increases (Wang et al., 2000).

\section{Impaired Glucose Tolerance}

Impaired glucose tolerance, also referred to as pre-diabetes, was defined according to American Diabetes Association (2008) criteria (fasting blood glucose $\geq 100$ and $<126 \mathrm{mg} / \mathrm{dl}$ or 2 -hr post-load glucose $\geq 140$ and $<200 \mathrm{mg} / \mathrm{dl}$ ). Thus, individuals with either elevated fasting or elevated 2-hour post-load glucose, whether measured during an oral glucose tolerance test or mixed meal tolerance test, were classified as having IGT.

Determination of IGT is of great significance. Within 10 years of diagnosis, $50 \%$ of adults with IGT progress to T2DM, and the risk of being diagnosed with cardiovascular disease doubles (Wylie, Hungin, \& Neely, 2002). In overweight and obese youth, the transition between IGT and T2DM is shortened compared to adults (Jolliffe \& Janssen, 2006), which may contribute to earlier manifestations of cardiovascular disease.

\section{Hypertension}

The National High Blood Pressure Education Program Working Group on High Blood Pressure in Children and Adolescent's normative blood pressure table was used to determine hypertension. Systolic blood pressure (SBP) or diastolic blood pressure (DBP) $\geq 95^{\text {th }}$ percentile was considered hypertension, pre-hypertension as $\geq 90^{\text {th }}$ but $<95^{\text {th }}$

percentile, and non-hypertension as $<90^{\text {th }}$ percentile for age, height, and sex (McNiece, Poffenbarger, Turner, Franco, Sorof, \& Portman, 2007). Pre-hypertension and hypertension blood pressure groups were then combined to form the elevated blood pressure group. 


\section{Heart Rate Variability}

Heart rate variability is the normal beat-to-beat alterations of heart rate and reflects the ANS's ability to respond to the environment (McMillan, 2002). Heart rate variability measurements were obtained from 24-hour Holter electrocardiogram recordings and derive from the analysis of consecutive R-R intervals (Gang \& Malik, 2003). The predominant method for analysis of HRV is time and frequency domain analysis, and these measurements also provide information about ANS activity (Gang \& Malik, 2003). Time domain analyses are calculated using mathematical equations, with measures reflecting parasympathetic modulation and circadian rhythmicity. The time domain measure utilized within this study is the standard deviation of all RR intervals (SDNN). This method was used because SDNN is a predictive HRV measure of mortality (Lampert, Ickovics, Horwitz, \& Lee, 2005). Sudden cardiac death has been linked to SDNN $<50 \mathrm{msec}$ (Faulkner, et. al, 2005). Power spectral analysis transforms variations in RR intervals into frequency waveforms reflecting sympathetic and parasympathetic modulation. The frequency domain measure used in this study was high frequency $(\mathrm{HF})$, which reflects parasympathetic modulation (Butera, Bonnet, Kachaner, Sidi, \& Villain, 2003). The HF measure was chosen for this study because it represents parasympathetic function exclusively (Faulkner et al., 2005). The low frequency measure represents a mixture of sympathetic and parasympathetic function (Faulkner et al., 2005) and therefore is not representative of sympathetic or parasympathetic function alone. Karavanaki-Karanassiou (2001) suggested that abnormalities in cardiac parasympathetic regulation precede impairment of blood vessels sympathetic control in youth with diabetes.

\section{QT Interval}

The QT Interval represents ventricular depolarization, and repolarization and is the measurement from the onset of the QRS complex to the end deflection of the T wave (Furukawa, Shimizu, Hiromoto, Kanemori, Masuyama, \& Ohyanagi, 2006; Hunt, 2005). The QT Interval normally ranges from $0.2-0.4 \mathrm{sec}$ and is often corrected to be independent of heart rate. According to the Harriet Lane Handbook $14^{\text {th }}$ edition (Barone, 1996), the QTc should not exceed $0.440 \mathrm{sec}$ in children and $0.425 \mathrm{sec}$ in adolescents and adults. The QT Interval adjusts to changes in heart rate (Barone, 1996; Moss \& Allen, 2001), and for comparison at different heart rates, correction formulas were developed to determine the QTc Interval, and Bazett's formula is used most often (Malik, Färbom, Batchvarov, Hnatkova, \& Camm, 2002).

\section{Left Ventricular Hypertrophy}

Left ventricular hypertrophy is enlargement of the ventricles (American Heart Association, 2007). This enlargement is often related to an increased workload on the heart muscle, which could be related to obesity or hypertension. The increased vascular resistance in the hypertensive person causes the heart to increase its workload and therefore the muscle enlarges to accommodate the body's requirement. 
Normative values have not been established in overweight or obese youth for electrical voltage measures for LVH. However, in obese adults, when using Cornell voltage criteria, in men when $\mathrm{S}_{\mathrm{V} 3}+\mathrm{R}_{\mathrm{aVL}}>2.8 \mathrm{mV}$ and in women $>2.0 \mathrm{mV}$, LVH was considered. Cornell voltage criterion $\left(\mathrm{S}_{\mathrm{V} 3}+\mathrm{R}_{\mathrm{aVL}}\right)$ has increased specificity and sensitivity in obese individuals, making this measure of LVH an appropriate choice.

\section{Assumptions}

The following assumptions were made for the purpose of the study:

- Impaired glucose tolerance in adolescents has a similar pathology to that identified in adults.

- Impaired glucose tolerance produces changes in autonomic function beyond that conferred by obesity.

- There are not significant age and gender differences in HRV among overweightobese adolescents.

- The Cornell criterion for measurement of LVH is appropriate for overweight and obese youth.

- Placement of the electrocardiogram leads for the 12-lead electrocardiogram and 24-hour Holter recording allowed for accurate electrocardiographic measurements in this sample of overweight-obese adolescents.

- Participants were compliant with the 10-hour fast prior to the oral glucose tolerance test conducted within the original study as advised, allowing accurate determination of glucose tolerance status.

- Anthropometrics data were accurately measured and recorded during the initial data collection period.

\section{Limitations}

Utilization of secondary data analysis was suitable for the research problem, although this design has both strengths and limitations. The secondary analysis of data allows the researcher to focus on a subgroup of the original sample to examine specific questions on readily available data. There are several limitations to the use of secondary analysis of data for completion of this study.

- The researcher had to assume the quality of the data was acceptable and was originally collected accurately and in congruence with the aims of the original researcher.

- Literature suggests that Cornell voltage $\left(\mathrm{S}_{\mathrm{V} 3}+\mathrm{R}_{\mathrm{aVL}}\right)$ is less influenced by the presence of obesity (Eckel, 2003), in adults. However, normative standards have not been developed for overweight-obese adolescents, and the use of adult standards may limit the results of this study.

- Age variations for HRV may exist (Faulkner, Quinn, Rimmer, \& Rich, 2005), however, the sample was too small to conduct sub-analysis by age. 
- Hypertension status was determined based on single blood pressure readings rather than multiple measurements, and room temperature or stress could influence study findings.

While these are limitations it was appropriate to examine these measures because they have not been previously examined in overweight and obese youth. In addition, results could suggest further investigation of these variables is warranted in overweight-obese youth. 


\section{CHAPTER 2. REVIEW OF LITERATURE}

\section{Introduction}

In the United States $25 \%$ of children are overweight and $11 \%$ are obese (Dehghan et al., 2005). This epidemic disease has transcended all racial groups with an exaggerated prevalence in non-whites (Caprio, Daniels, Drewnowski, Kaufman, Palinkas, Rosenbloom, \& Schwimmer, 2008). The incidence of childhood overweight-obesity has increased substantially within the United States, accompanied by the risk for the development of many secondary conditions that may progress into adulthood. While most complications of childhood obesity develop over the course of years, cardiovascular health risks and IGT may present at a younger age with the progression from IGT to T2DM shortened (Jolliffe \& Janssen, 2006). However, there is limited information on the effect of obesity on autonomic function in youth.

This review of literature integrates relevant concepts proposed in the conceptual framework. The first section provides an overview of adolescent obesity. Subsequent sections address autonomic nervous system function in adolescents by examining HRV, QT Interval duration, hypertension, and LVH variations based on age, gender, race, and obesity. Following those sections is an examination of the effects of IGT with concomitant obesity on autonomic function.

\section{Obesity in Adolescents}

The National Health and Nutrition Examination Survey, a representative sample of the United States population, found $17.6 \%$ of adolescents are obese (Centers for Disease Control, 2009). Childhood obesity is associated with obesity as an adult (Guo, Wu, Chumlea, \& Roche, 2002), and multiple studies link childhood obesity to subsequent morbidity and mortality in adulthood (DiPietro, Mossberg, \& Stunkard, 1994; Must, Jacquez, Dallal, Bajema, \& Dietz, 1992; Nieto, Szklo, \& Comstock, 1992). A longitudinal follow-up of adolescents in the Harvard Growth Study documented that being an overweight adolescent male increased relative risk of all-cause mortality $(\mathrm{RR}=$ $1.8)$ and mortality from coronary heart disease $(\mathrm{RR}=2.3)$ regardless of weight at age 55 (Must, Jacquez, Dallal, Bajema, \& Dietz, 1992).

Obesity is a risk factor for a myriad of chronic diseases including cardiovascular disease (CVD) and T2DM, and these conditions are now being found in obese children (Goran, Ball, \& Cruz, 2003; Khositseth, Suthutvoravut, Chongviriyaphan, \& Ruangkanchanasetr, 2006). It has been reported that while most complications of childhood obesity develop over the course of years, cardiovascular health risks and IGT may present at a younger age, with the progression from IGT to T2DM shortened (Jolliffe \& Janssen, 2006). Fifty-eight percent of overweight children have at least one cardiovascular risk factor or an elevated insulin level, and up to $25 \%$ have two risk factors or more (Plourde, 2006). Yet there are very few studies in obese children that 
examine autonomic function (Kaufman, Kaiser, Steinberger, \& Kelly, 2007), cardiovascular function (Khositseth, Suthutvorvut, Chongviriyaphan, \&

Ruangkanchanasetr, 2006), or electrocardiographic changes. The health problems that emerge secondary to obesity in children may progress throughout their lifespan (Obesity Society, 2009), and early prevention and screening by healthcare providers is essential if childhood obesity is suspected.

Acceptable screening methods that can be used to assess for childhood obesity include BMI [(weight $(\mathrm{kg}) /$ height $\left.^{2}\left(\mathrm{~m}^{2}\right)\right]$ and RBMI $\left[\mathrm{BMI} /\left(\mathrm{BMI}^{50 \text { th }}\right.\right.$ percentile for age and sex $* 100)]$. In adolescents, overweight is defined as a BMI $\geq 85^{\text {th }}$ percentile and obesity as a $\mathrm{BMI} \geq 95^{\text {th }}$ percentile based on age, height, and gender percentile distributions (O'Brien et al., 2007). Although BMI is not a direct measure of body fatness, BMI is noninvasive, highly reliable, (Centers for Disease Control, 2008), and found to be related to obesity-associated complications (Rubenstein, 2005). Normative values for BMI vary by age and gender, making comparisons across groups difficult. However, RBMI is a continuous variable derived from BMI which provides a measure of obesity severity and is useful for tracking obesity progression and which facilitates comparison across age and sex groups (Velasquez-Mieyer, Perez-Faustinelli, \& Cowan, 2005; Wang et al., 2000). Relative body mass index could prove to be beneficial for clinicians monitoring obesity in the aging child (Velasquez-Mieyer et al., 2005). As a child ages, the amount of expected body fat changes; however, RBMI remains relatively stable as age increases (Wang et al., 2000). Despite overwhelming evidence suggesting that BMI and RBMI measures are noteworthy in screening for obesity, a survey of pediatricians found that only $29 \%$ of pediatricians routinely assessed BMI (Flower, Perrin, Viadro, \& Ammerman, 2007), supporting contentions that overweight-obesity is often under diagnosed in adolescents.

Current screening recommendations for obese children include healthcare providers performing a full examination with history, lipid profile, blood pressure measurement, and screening for T2DM (Plourde, 2006) using fasting insulin and glucose levels. However, IGT is diagnosed more effectively with an oral glucose tolerance test than fasting blood sugar alone (Cruz et al., 2005), and should be considered when examining obese youth for IGT. Researchers have suggested that current screening recommendations in obese youth underestimate risk for diabetes and cardiovascular disease. Examination of additional risk factors is warranted, particularly in minority populations where the disease burden is greater (Velasquez-Mieyer, Niera, Nieto, \& Cowan, 2007). Examination of cardiac risk factors of HRV, QTc duration, and electrical voltage measures of $\mathrm{LVH}$, which are modulated by autonomic function, may aid in identifying obese youth at increased risk for obesity-associated co-morbidities.

\section{Autonomic Nervous System Function}

Sympathetic and parasympathetic stimulation of the ANS regulates cardiac muscle, smooth muscle, and glands of the body. The ANS is part of the efferent output of the energy balance pathways that mediates changes in energy expenditure vs. storage 
(Lustig, 2001), and associations between sympathetic stimulation and obesity have been identified (Sekine et al., 2001). Obesity is usually associated with increased sympathetic nervous system activity, which may be important in the development of the cardiovascular sequelae seen in many obese individuals. Conversely, postprandial insulin hypersecretion has been postulated to be driven by parasympathetic activation of the pancreatic beta cells through the pancreatic branch of the vagus nerve (Lustig, 2003). Over time, chronic sympathetic stimulation may inhibit insulin secretion from the beta cells (Carnethon et al., 2006), further contributing to insulin resistance and IGT. Investigators examining cardiac autonomic function in obese adults have reported a relative decrease in parasympathetic function in comparison to sympathetic function (Gutin, Barbeau, Litaker, Gerguson, \& Owens, 2000). These studies suggest that both alterations in sympathetic and parasympathetic activity occur in concert with obesity. Whether alterations in ANS function contribute to obesity or are a consequence of obesity remains unknown (Tentolouris, Liatis \& Katsilambros, 2006).

The ANS regulates heart rate and blood pressure. Epinephrine and norepinephrine released by the sympathetic nervous system and acetylcholine released by the parasympathetic nervous system are major influences on heart rate and rhythm (Alter et al., 2006). Therefore, in light of cardiac automaticity, heart rate is largely controlled by ANS function (Alter et al., 2006). Factors affecting cardiac autonomic function examined within this study included HRV, QTe duration, hypertension, and electrical voltage measures for $\mathrm{LVH}$.

Heart rate variability is the normal beat-to-beat alterations of heart rate and reflects the autonomic nervous system's ability to respond to the environment (McMillan, 2002). It is modulated by both sympathetic and parasympathetic activity (Bilchick \& Berger, 2006). The QT Interval is the measurement from the onset of the QRS complex to the end deflection of the $\mathrm{T}$ wave and represents ventricular depolarization and repolarization (Furukawa et al., 2006; Hunt, 2005). It is also modulated by autonomic function (Viitasalo et al., 1998). Hypertension, a risk factor for the development of LVH, is associated with sympathovagal imbalance and vagal withdrawal (Pal et al., 2009).

\section{Heart Rate Variability}

Limited information regarding HRV in healthy adolescents has been reported; thus large data sets are not available for the establishment of normative values. Additionally, comparisons across studies have been hindered by varying methods used to collect HRV data, with measurements being derived from ranges of 24-hours to as little as 5-minute time periods.

\section{Heart Rate Variability: Age and Gender Effects}

Massin and Von Bernuth (1997) and Silvetti, Drago, \& Ragonese (2001) reported that HRV measures of circadian fluctuation increased from infancy through early 
adolescence along with associated maturational decreases in heart rate. Similarly, Galeev, Igisheva, \& Kazin (2002) found that in children 6 to 16 years of age, circadian fluctuation (SDNN values) increased with age, as did high frequency (HF) values, reflecting increased parasympathetic function.

Contradictory findings on gender differences for HRV have been reported in the literature and may be reflective of small sample sizes for various age groups, differences in measurement techniques, and/or the effect of physical activity levels on HRV measures. Faulkner, Hathaway, and Tolley (2003) examined gender differences in HRV and reported adolescent males $(n=26)$ exhibited higher circadian fluctuation (SDNN) and higher parasympathetic function (HF) measures than adolescent females $(n=49)$. Similarly Silvetti, Drago, \& Ragonese (2001) reported greater circadian rhythmicity, measured by SDNN, in males compared to females. In contrast, Galeev, Igisheva, \& Kazin (2002) reported gender differences in HRV measures of low frequency and SDNN during early adolescence, which disappeared at 16 years of age.

\section{Heart Rate Variability: Racial Differences in Children}

Black adolescents, in comparison to white peers, have been noted to have lower HRV measures of circadian fluctuation (SDNN) and parasympathetic function (HF), although values were not significantly different (Faulkner et al., 2003). Similarly, Gutin, Howe, Johnson, Humphries, Snieder, and Barbeau (2005) found lower parasympathetic (HF) measures in black adolescents compared to whites and also a lower low frequency (LF): high frequency (HF) ratio after adjusting for age. Contrary to these findings in youth, black adults had higher measures of parasympathetic function (HF) than whites and also lower sympathetic (LF) function (Liao, Barnes, Chambless, Simpson, Sorlie, \& Heiss, 1995). Similarly, a small group of healthy black male adolescents were reported to have a diminished sympathetic tone compared to white peers (Urbina, Bao, Pickoff, \& Berenson, 2002). The majority of studies were not sufficiently powered to examine multiple covariates, which include physical fitness, physical activity, obesity, and hypertension that could affect HRV measures. However, collectively these studies suggest that race should be considered when assessing HRV in adolescents.

\section{Heart Rate Variability and Childhood Obesity}

Cross-sectional studies have shown that HRV measures of parasympathetic nervous system function are decreased in obese children compared to normal weight children, although contradictory findings have been reported regarding the relationship of obesity to sympathetic measures and sympathetic/parasympathetic balance (Kaufman et al, 2007; Martini, Riva, Rabbia, Molini, Ferrero, Cerutti, et al., 2001; Rabbia et al., 2003; Sekine et al., 2001). The majority of these studies have consisted of small sample sizes. Kaufman et al (2007) examined HRV measures in normal weight $(\mathrm{n}=10)$, overweight ( $\mathrm{n}$ $=10)$, and obese $(n=16)$ 10-13-year old youth using 5-minute resting electrocardiogram data. Obese children exhibited a significantly higher low frequency (LF)/high frequency 
(HF) ratio indicating sympathetic predominance and lower parasympathetic measures $(\mathrm{HF})$ compared to normal weight children, and there was a trend $(\mathrm{p}<0.07)$ toward lower measures of circadian fluctuation (SDNN). The obese children were also more insulin resistant and had higher systolic blood pressures (Kaufman et al., 2007). Similarly, a study of school-aged Japanese children matched for age, gender, and height found obese children $(n=42)$ had significantly lower LF and HF HRV measures compared to normal weight peers $(n=42)$, suggesting both sympathetic and parasympathetic function are diminished in obese youth (Nagai, Matsumoto, Kita, \& Moritani, 2003). Additionally, in the presence of autonomic imbalance, decreases in SDNN have been reported in overweight adolescents (Guizar, Ahuatzin, Amador, Sanchez, \& Romer, 2005).

The pattern of sympathetic and parasympathetic dysfunction may be affected by the duration of obesity. Obese adolescents $(n=50)$ were stratified based on duration of obesity and compared to 12 lean peers (Rabbia et al., 2003). Parasympathetic measures were lower in obese youth, regardless of duration of obesity, compared to normal weight youth. However, compared to the normal weight group, only the recently obese group exhibited a significantly higher LF and LF: HF ratio, reflecting higher sympathetic function and higher sympathetic/parasympathetic balance (Rabbia et al., 2003). Consistent with these findings, Nagai et al (2003) reported that longer duration of obesity was associated with lower LF and HF measures of HRV.

The literature supports the beneficial effect of weight loss and fitness training on HRV measures. Obese adults treated with either bariatric surgery or dietary management were studied to determine the effect of weight loss on HRV measures (Karason, Mølgaard, Wikstrand, \& Sjöström, 1999). Weight loss in the surgical group was $32 \mathrm{~kg}$ compared to no change in the dietary group, and the surgical group demonstrated improvements in blood pressure, decreases in norepinephrine excretion, and improved sympathetic and parasympathetic measures (Karason et al., 1999). Recently published studies involving small numbers $(n=10-12)$ of adults undergoing bariatric surgery for weight loss have reported post-surgery weight loss increases in circadian fluctuation (SDNN) (Bobbioni-Harsch, Sztajzel, Barthassat, Makoundou, Gastaldi, Sievert, et al., 2009; Nault, Nadreau, Paquet, Brassard, Marceau, Marceau, et al., 2007), parasympathetic function (HF) and sympathetic function (LF) (Nault et al., 2007). No studies were found examining the effect of weight loss alone on HRV in obese youth.

In older adults ( $>50$ years of age), regular physical activity appears to attenuate the negative effects of obesity on HRV measures (Felber, Ackermann-Liebrich, Schindler, Barthélémy, Brändli, Gold, et al., 2008). Baseline and 10-year follow-up HRV, BMI, and physical activity measures were assessed in 1,712 adults to determine the relationship between these variables and the effect of weight gain on changes in HRV measures. Compared to sedentary obese adults, sedentary normal weight adults had a $14 \%$ higher SDNN, while normal weight exercisers and obese exercisers had a $19 \%$ higher SDNN (Felber et al., 2008).

Lower sympathetic and parasympathetic measures of HRV have been reported in obese youth compared to normal weight youth, controlling for physical activity, age, 
gender, and height (Nagai \& Moritani, 2004). In one of the few reports involving a mixed racial sample of 304 adolescents from the United States, the relationship of physical activity and adiposity to HRV measures was examined, controlling for age, race, and gender (Gutin, Howe, Johnson, Humphries, Snieder, \& Barbeau, 2005). Engagement in more vigorous physical activity and lower adiposity was associated with a more favorable HRV profile, with higher adiposity having a more deleterious effect on HRV in black than in white youth (Gutin et al., 2005). Exercise training programs improve parasympathetic function (HF) in obese adolescents (Gutin et al., 2000) and reduce the ratio of sympathetic to parasympathetic activity (Gutin, Owens, Slavens, Riggs, \& Treiber, 1997).

\section{Summary of Studies Examining Heart Rate Variability}

Heart rate variability measures change during childhood as a result of maturation, with HF and SDNN values stabilizing during adolescence when normal heart rate values reach adult values. Contradictory findings on gender and racial differences in HRV measures have been reported. Obesity is associated with lower HRV measures of sympathetic and parasympathetic function, with duration of obesity affecting the relationship between obesity and sympathetic function. Physical activity improves parasympathetic function and results in a more favorable sympathetic/parasympathetic balance. Physical activity may also attenuate some of the obesity-associated decreases in HRV measures.

\section{QT Interval Duration}

The QT Interval, measured from the onset of the QRS complex to the end of the T wave, represents ventricular depolarization and repolarization (Furukawa et al., 2006; Hunt, 2005) and is modulated by autonomic nervous system function (Viitasalo et al., 1998). The autonomic nervous system influences both cardiac repolarization and QT length directly through its effect on heart rate.

Prolongation of the QTc Interval (delay in ventricular repolarization) predisposes the heart to arrhythmias, with the most commonly caused arrhythmia being Torsades de Pointes (Antzelevitch, 2005; Lanjewar et al., 2004; QT Syndrome, 2005; Texas Heart Institute, 2007; Toivonen, 2002;). Torsades de Pointes can lead to sudden cardiac death (Lanjewar et al., 2004; QT Syndrome, 2005). Although prolonged QTc duration increases the individuals overall probability of arrhythmias the critical threshold is suggested to be $0.550 \mathrm{sec}$ (Suys, Heuten, De Wolf, Verherstraeten, de Beeck, Matthys, et al., 2006). While long QT syndrome has been studied in youth, there is a paucity of information on QTc Interval duration in obese youth and on the relationship of QTc duration to other cardiac autonomic measures. 


\section{QT Interval Duration: Age and Gender Effects}

The QT Interval normally ranges from $0.2-0.4 \mathrm{sec}$ and adjusts to changes in heart rate (Barone, 1996; Moss \& Allen, 2001). It has been noted that considerable heart rate variations are present throughout childhood, which makes correction of the QT Interval in children essential (Prasad, Furr, Zhang, Ball, \& Allen, 2007). Bazett's correction formula is often used to calculate the corrected QT (QTc) Interval, which adjusts for heart rate (Malik et al., 2002). This correction formula is easy to use but has been known to over correct at extremely fast heart rates and under correct at very slow heart rates (Desai, Li, Desta, Malik, \& Flockhart, 2003); however, research suggests that there is no optimal correction formula (Malik et al., 2002).

According to the Harriet Lane Handbook $14^{\text {th }}$ edition (1996), the QTc should not exceed $0.44 \mathrm{sec}$ in children and $0.425 \mathrm{sec}$ in adolescents and adults. When using the 12lead electrocardiogram, the QT Interval is often obtained manually by measuring 3 consecutive QT Intervals in lead II and correcting for heart rate utilizing Bazett's formula (Rana, Lim, Naas, Ogston, Newton, Jung, et al., 2005). Prolongation of the QT Interval is strongly related to sudden cardiac death and the autonomic nervous system influences diurnal variation (Yeragani, Berger, Pohl, \& Balon, 2005).

Prior to puberty, QT Interval duration is similar between genders; however, at puberty, the QTc Interval shortens in boys, and a variation in the pattern of ventricular repolarization is seen between genders (Surawicz \& Parikh, 2003). These findings of shorter QTc Intervals in boys are consistent with data reported by Pearl (1996). In a sample of 781 healthy 10-18 year olds, Pearl (1996) found that QTc Intervals were greater in girls than boys across age ranges, and QTc varied inversely with age and directly with heart rate.

\section{QT Interval Duration: Racial Differences in Children}

There is a paucity of research examining QT Interval duration and race in adolescents. However, a study in adults suggests that QTc is shorter in healthy blacks than whites (Dekker, Crow, Hannan, Schouten, \& Folsom, 2004). Challenging these findings, researchers identified contrary results but acknowledged a small sample size as a possible limitation (Sgarbossa, Pinski, Williams, Pavlovic-Surjancev, Tang, \& Trohman, 2000). Researchers have also suggested that race in general is not considered a risk factor for QT prolongation (Peeters, Janssen, Kakuda, Scholler-Gyure, Lachaert, Hoetelmans, et al., 2008). Although conflicting results have been identified in adults, published studies examining race and QT Interval duration in overweight-obese adolescents were not identified during this review of literature. 


\section{QT Interval Duration and Childhood Obesity}

Obese individuals are at an increased risk for the development of arrhythmias associated with QT Interval prolongation (El Gamal, Gallagher, Nawras, Gandhi, Gomez, Allison, et al., 1995). Through direct neural effects on the heart, the ANS influences QT Interval duration (Haapalahti et al., 2006), potentially leading to lethal arrhythmias. Most individuals with prolonged QT Interval duration are at risk for cardiac arrhythmias during sympathetic stimulation as a result of increases in heart rate (Haapalahti et al., 2006).

Obesity may be one of the most common causes of prolonged QT duration, with significant associations to RBMI (El Gamal et al., 1995) as well as a positive association between BMI and QT Interval duration (Poirier, Giles, Bray, Hong, Stern, Pi-Sunyer, et al., 2006). Similarly, Spanish obese youth $(n=30)$ exhibited longer QTc, greater volume and mass of the left ventricle, and greater risk of arrhythmias compared to normal weight youth $(\mathrm{n}=30)$ (Olivares Lopez, Vazquez Olivares, Fleta Zaragozano, Moreno Aznar, Bueno Sanchez, 2005). Contrarily, some researchers have noted a lack of correlation between QT Interval and BMI (Fukushige, Yoshinaga, Shimago, Nishi, Kono, Nomura, et al., 2002; Girola, Enrini, Garbetta, Tufano, \& Cariezel, 2001). The majority of studies examining the relationship of weight to QT Interval duration have been conducted in non-United States (US) populations; thus studies examining relationships between BMI and QTc Interval duration in US adolescents are needed.

\section{QT Interval Duration and Heart Rate Variability}

Few studies have examined relationships between QT Interval duration and HRV, and literature identified were more likely to examine these variables in conjunction with one another rather than in relation to one another (Bilan, Witczak, Palusinski, Ignatowicz, $\&$ Hanzlik, 2005). Circadian variation of autonomic tone is believed to affect QT Interval duration (Ishida, Nakagawa, Fujino, Yonemochi, Saikawa, \& Ito, 1997). High frequency component, overall HRV measures, and QT Interval duration have shown to correlate in adult subjects (Viitasalo et al., 1998). A negative correlation with R-R interval and high frequency power (reflecting parasympathetic function) for QT Interval duration has been reported in adults (Ishida et al., 1997). Nonetheless, Viitasalo and colleagues (1998) have indicated that the QT Interval is modulated by autonomic function, which supports simultaneous examination of these variables in overweight-obese adolescents.

\section{Summary of Studies Examining QT Interval Duration}

Age and gender may affect QTc Interval duration during childhood. However, age effects are attenuated during adolescence, and gender differences manifest, with postpubescent males tending to have a shorter QTe duration than females of similar age. Contradictory findings have been reported when examining racial differences in QTc Intervals; thus further investigation in this area is warranted. Obesity and QTc duration are positively correlated, although QTc duration may fall within the upper limits of 
normal in obese youth. Studies examining the relationships between HRV measures and QTc Intervals in adolescents were not found. However, adult studies suggest lower HRV measures of parasympathetic function and circadian fluctuation are associated with longer QTc Intervals.

\section{Left Ventricular Hypertrophy}

Neuroreceptors of the autonomic nervous system located on heart muscle can affect heart rate, contraction, conduction, and automaticity. Autonomic dysfunction may result in increased blood pressure due to increased sympathetic outflow to blood vessels, leading to vasoconstriction and a hypertensive state, thus contributing to the occurrence of LVH. Periods of sympathetic nervous system arousal are expected in day-to-day activity, although prolonged stimulation of the sympathetic nervous system is often characterized as a contributing factor to hypertension (McMillan, 2002) due to resulting vasoconstriction. The increased vascular resistance in the hypertensive person causes the heart to increase its workload; therefore, the muscle enlarges to accommodate the body's requirement, which is known as $\mathrm{LVH}$.

\section{Left Ventricular Hypertrophy and 12-Lead Electrocardiogram Criteria}

Typically the echocardiogram (Gertsch, 2004) or magnetic resonance imaging (Alfakih, Walters, Jones, Rigway, Hall, \& Sivananthan, 2004) are used as the preferred diagnostic methods of LVH. The suggested electrocardiographic criteria for diagnosing LVH may be either voltage or non-voltage criteria, although there is no preferred method (Edhouse, Thakur, \& Khalil, 2002). The 12-lead electrocardiogram has been validated as a measure of detecting LVH compared to the echocardiogram and magnetic resonance imaging methods; however, it is not recommended that the electrocardiogram be used alone to diagnose LVH (Pewsner, Juni, Egger, Battaglia, Sundstrom, \& Bachmann, 2007). The electrocardiogram is an excellent screening measure and is valued as an initial diagnostic test for left ventricular hypertrophy (Rijnbeek, van Herpen, Kapusta, Ten Harkel, Witsenburg, \& Kors, 2008). While none of these tests are routinely performed in children, the electrocardiogram is performed more frequently than echocardiogram and magnetic resonance imaging and can also detect rhythm or conduction defects.

When used as a screening tool, the electrocardiogram can be extremely beneficial. Early detection of LVH is very important in children, because if left undiagnosed and untreated, the risk of sudden cardiac death is greatly increased. Other benefits of using the electrocardiogram for early detection of LVH include the ability to interpret the results more rapidly, cost savings (as the electrocardiogram is estimated to cost only $20 \%$ of the amount for an echocardiogram), and specificity is equivalent to that of the echocardiogram (approximately 90\%). However, the sensitivity or likelihood of false positive results is $20-35 \%$ using the electrocardiogram to detect LVH (Gertsch, 2004). 
The Cornell voltage index is a more recently published criterion for measuring LVH by electrocardiogram. It has been shown to be more effective in measuring LVH in obese adults than other criteria (Eckel, 2003). But like many other electrocardiographic criteria that have been shown to improve detection of LVH in adults, this criteria has not been tested in children (Rijnbeek et al., 2008).

\section{Left Ventricular Hypertrophy: Age and Gender Effects}

Normative values of electrical voltage measures for LVH have not been established in healthy or overweight-obese children, based on age or gender. However, it is clearly stated within the literature that adolescent girls have lower amplitude for Q, R, and $\mathrm{S}$ wave, in regards to size or body mass index (Semizel, Ozturk, Bostan, Cil, \& Ediz, 2008). Fatty tissue over the chest during growth, which includes breast tissue in girls, could be related to the lower amplitude in girls (Semizel et al., 2008). The Cornell voltage criteria for $\mathrm{LVH}$ provide gender-specific cut points, which correlate with echocardiogram and magnetic resonance imaging of LVH (Alfakih et al., 2004). Left ventricular hypertrophy is diagnosed when electrocardiogram voltage $\left(\mathrm{S}_{\mathrm{V} 3}+\mathrm{R}_{\mathrm{aVL}}\right)$ exceeds $2.8 \mathrm{mV}$ in men and exceeds $2.0 \mathrm{mV}$ in women. Cornell voltage criterion $\left(\mathrm{S}_{\mathrm{V} 3}+\right.$ $\mathrm{R}_{\mathrm{aVL}}$ ) is affected far less by the presence of obesity and should be used in adults when obesity is present (Eckel, 2003). However, it is unknown whether these voltage cut points of LVH in adults are relevant in adolescence.

\section{Left Ventricular Hypertrophy: Racial Differences in Children}

Cardiovascular mortality resulting from $\mathrm{LVH}$ is greater in blacks than whites, which may be related to the higher incidence of hypertension in blacks vs. whites (Coughlin, Gottdiener, Baughman, Wasserman, Marx, Teft, et al., 1994; Drazner, 2004). However, regardless of race, childhood obesity is associated with a clustering of cardiovascular risk factors, including hypertension (Caprio et al., 2008). Investigations are needed to determine if race affects the development of LVH, particularly in the presence of concomitant obesity and hypertension, in adolescents, because early identification and treatment may prevent cardiac mortality.

\section{Left Ventricular Hypertrophy and Childhood Obesity}

Flynn and Alderman (2005) reported a linkage between obesity, hypertension, and $\mathrm{LVH}$, it has also been noted that LVH may develop very early in obese adolescents (Khositseth et al., 2006). Researchers reported that children who appeared to be a healthy weight but were actually overweight, had begun to develop LVH, a fact that stresses the importance of BMI calculation in relation to screening for LVH (Cincinnati Children's, 2007). 
In obese individuals, electrical forces within the heart become more posterior, and the $\mathrm{S}_{\mathrm{V} 3}$ is the most representative voltage for evaluating posterior electrical forces (Eckel, 2003). When LVH is present, the heart in obese individuals is shifted more horizontally in the chest cavity, which elucidates the importance of the $\mathrm{R}_{\mathrm{aVL}}$ (Eckel, 2003), part of the Cornell criteria for $\mathrm{LVH}$.

The most common cause of LVH is systemic hypertension (Edhouse et al., 2002). In $34-38 \%$ of children with even mild untreated hypertension, LVH has been identified and childhood obesity is an additional risk for the development of LVH (Ippisch \& Daniels, 2008). Khositseth and colleagues (2006) have shown no correlation between high blood pressure and obesity or severity of obesity, though this could be related to the small number of participants who were hypertensive and the relatively small sample size. Interestingly, in a small study of Spanish obese youth $(\mathrm{n}=30)$ a greater volume and mass of the left ventricle compared to normal weight youth was exhibited $(n=30)$; however, information on the hypertensive status of the children was not available (Olivares Lopez et al., 2005).

\section{Left Ventricular Hypertrophy/Hypertension and Heart Rate Variability}

There is a paucity of research examining HRV in the presence of LVH. Studies were not identified that examined these variables collectively in adolescents. In one study, adults with concomitant hypertension and hypertrophic cardiomyopathy had reduced SDNN measures of HRV, with greater reductions in HRV linked to increased hypertrophy (Alter, Grimm, Vollrath, Czerny, \& Maisch, 2006). In contrast, another study noted no significant differences in HRV measures when mild hypertension was present (Franchi, Lazzeri, La Villa, 1996). Studies examining the relationship of HRV to hypertension have yielded equivocal results, which may be partially attributed to the confounding effects of physical activity and concomitant obesity. Researchers have shown the linkage between increased sympathetic (Sorof \& Daniels, 2002) and reduced parasympathetic (Gutin et al., 2000) tone to hypertension in obese youth. Similar findings were reported by Urbina and colleagues (2002), with a trend toward higher sympathetic and lower parasympathetic measures occurring in adolescent males with diastolic blood

pressure exceeding the $85^{\text {th }}$ percentile. Literary findings in children support the association between an altered sympathetic-vagal balance and hypertension (Guizar et al., 2005), but the children in this study who were hypertensive also tended to be overweight or obese.

\section{Left Ventricular Hypertrophy/Hypertension and QT Interval Duration}

QTc Interval prolongation has been identified in children with hypertension (Kocak, Atalay, Bakkalog, Ekim, \& Ayten, 1999) and obese patients (Takebayashi, Aso, Matsutomo, Wakabayashi \& Inukai, 2004). Higher systolic and diastolic blood pressure measures were associated with longer QTc Interval duration (Takebayashi et al., 2004). 
In addition, QT peak identified hypertensive patients likely to have LVH (Wong, Lim, Wong, MacWalter, Struthers, \& MacDonald, 2003).

In adults, LVH increased the incidence of QTc Interval prolongation (Kulan, Ural, Komsuoglu, Agacdiken, Goldeli, \& Komsuoglu, 1998). This is theorized to result from myocardial alterations due to LVH affecting action potential and the duration of myocardial repolarization, resulting in prolonged QT Interval duration (Kulan et al., 1998). In a study examining hypertension in adults, no significant differences in QTc Interval duration or HRV were noted when mild hypertension was present (Franchi et al., 1996).

It is of great concern that electrocardiograms are not routinely performed on adolescents. Current indications for obtaining an electrocardiogram in children only include syncope, exertional symptoms, tachyarrhythmias, bradyarrhythmias, and drug ingestion (Goodacre \& McLeod, 2002). Therefore, it is important that hypertension be properly diagnosed and treated in children to decrease the risk of QT prolongation and LVH that may potentially result in sudden cardiac death.

\section{Summary of Studies Examining Left Ventricular Hypertrophy}

Obesity and hypertension, even mild untreated hypertension, are associated with increased risk for LVH. Blacks were more likely than whites to develop LVH, which has been linked to the higher prevalence of hypertension in blacks than whites. Hypertension is prevalent among obese youth, increasing their risk for LVH. Prolonged QT Interval has been identified in children with hypertension and in adults with hypertension and/or left ventricular hypertrophy. Linkages between HRV and LVH have not been elucidated in adolescents. Limited research has been conducted in adults examining HRV and LVH with reduced SDNN measures occurring when hypertension and hypertrophy co-existed. Studies examining the relationship of HRV to hypertension have yielded equivocal results, which may be partially attributed to the confounding effects of physical activity and concomitant obesity.

\section{Impaired Glucose Tolerance in Overweight-Obese Youth}

Obesity is linked to the rise in T2DM; nearly half of all adolescents diagnosed with T2DM are obese (Cruz et al., 2005). Type 2 diabetes is being diagnosed more frequently in minority adolescents with concomitant obesity (Centers for Disease Control, 2009). Current recommendations include screening obese children for diabetes using fasting glucose values, with concomitant insulin levels drawn (Plourde, 2006), which provide a measure of beta-cell function. Advantages for use of the fasting glucose for diabetes screening include low cost and convenience. However, in obese adolescents, single fasting blood glucose may not detect early deterioration in glucose metabolism, resulting in missed opportunities for intervention (Velasquez-Mieyer et al., 2007). Fasting blood glucose has been shown to be a poor predictor of diabetes in obese 
adolescents and subjects with polycystic ovarian syndrome (Legro, Kunselman, Dodson, \& Dunaif, 1999). Glucose and insulin indices derived from an oral glucose tolerance test help evaluate the relationship among adiposity, beta-cell secretory capacity, and insulin action in those children at higher risk to develop diabetes to determine which treatment approach is necessary (Velasquez-Mieyer et al., 2007). The American Diabetes Association (ADA) estimates that 2 million adolescents $(17 \%)$ have pre-diabetes (American Diabetes Association, 2008) while others have reported IGT (pre-diabetes) in up to $25 \%$ of obese youth (Plourde, 2006). These numbers may be underestimated, given that most screenings use fasting values which have been reported to miss between 37 to $66 \%$ of overweight adolescents with pre-diabetes, based on oral glucose tolerance test glucose values (Velasquez-Mieyer et al., 2007). Studies that report higher rates of prediabetes may have included individuals with greater severity of obesity, or investigators may have used more sensitive measures to assess glucose intolerance. The progression from pre-diabetes to diabetes is shorter in children than adults (Jolliffe \& Janssen, 2006) and complications may manifest earlier in the disease process.

\section{Glucose Intolerance and Autonomic Dysfunction}

While the pathogenesis of diabetic autonomic dysfunction has not been thoroughly established, it has been postulated that prolonged exposure to metabolic derangements leads to chronic, widespread neural lesions, with loss of both myelinated and unmyelinated axons (Greene, Feldman, Stevens, Sima, Albers, \& Pfeifer, 1997; Simmons, 1994; Solders, Persson, \& Wilczek, 1986). Accumulation of glucose in nerve fibers with a slowing of neural conduction, impaired lipid synthesis, and changes in myelin composition/synthesis may contribute to axon damage (Clarke, Ewing, \& Campbell, 1979; Hoskings, Bennett, \& Hampton, 1978).

While autonomic function is adversely affected by chronic elevations in glucose, conversely autonomic alternations contribute to the development of IGT. Insulin release is stimulated by parasympathetic activation and sympathetic activation inhibits insulin secretion (Bloom, Edwards, \& Hardy, 1978; McCance \& Huether, 2002). Postprandial insulin hypersecretion has been postulated to be driven by parasympathetic activation of the pancreatic beta cells through the pancreatic branch of the vagus nerve (Lustig, 2003). Over time, chronic sympathetic simulation may inhibit insulin secretion from beta cells (Carnethon et al., 2006), contributing to insulin resistance and IGT.

\section{Glucose Intolerance, Obesity, and Heart Rate Variability}

Reports from the Artherosclerosis Risk in Communities Study (Carnethon, Golden, Folsom, Haskell \& Liao, 2003) and the Coronary Artery Risk Development in Young Adults (CARDIA) study (Carnethon, Jacobs, Sidney, \& Liu, 2003) suggest that changes in autonomic function predict the future development of T2DM. Recently, posthoc analysis of data from the Diabetes Prevention Program (DPP) was conducted to examine whether autonomic function predicted the development of T2DM in adults with 
IGT, many with concomitant obesity (Carnethon et al., 2006). In this population, there was no association between baseline HRV measures of sympathetic and parasympathetic function nor QT Interval measures with the development of T2DM, although baseline heart rate was modestly related to the development of T2DM across all treatment arms of the study (Carnethon et al., 2006). However, it is unknown whether these HRV measures, derived from a single 12-lead EKG, would differ from those seen in obese adults without IGT. Many uncertainties surround the effects of glucose metabolism on HRV in obese adolescents; however, HRV changes have been noted in patients with diabetes (McMillian, 2002).

In adults with T2DM, impaired HRV, with decreased circadian fluctuation, has been recognized as a risk factor for sudden cardiac death, and autonomic dysfunction increases, with increased metabolic glucose impairment (Periaccante et al., 2006). Earlier work by Singh, Larson, O’Donnell, Wilson, Tsuji, Lloyd-Jones, et al., (2000) revealed that fasting blood glucose levels were inversely correlated with HRV measures of SDNN, $\mathrm{HF}$, and LF ( $\mathrm{r}=-0.21$ to -0.26$)$ although the strength of the association diminished after adjusting for multiple covariates of age, sex, heart rate, body mass index, antihypertensive and cardiac medications, systolic and diastolic blood pressures, smoking, and alcohol and coffee consumption. Compared to those with normal fasting glucose levels, individuals with diabetes and IGT exhibited reduced HRV values for SDNN, LF, and $\mathrm{HF}$, and $\mathrm{LF} / \mathrm{HF}$ ratio. After adjusting for the clinical covariates, the impaired glucose tolerant group continued to have poorer HRV measures compared to the normal glucose group, although these differences were not statistically significant, while statistically significant differences in the LF power and LF/HF ratio (measures of sympathetic function) remained between the normal glucose group and the diabetic group (Singh et al, 2000).

Studies examining differences in autonomic function between adolescents with type 1 diabetes and those with normal glucose levels support findings from adult studies, documenting autonomic dysfunction in those with diabetes (Faulkner et al., 2003; Massin \& von Bernuth, 1999; Wawryk, Bates, \& Couper, 1997). Even with good metabolic control, HRV was significantly reduced in children of all ages with type 1 diabetes (ages $3-18, N=73$ ) (Massin et al., 1999). Impairments in HRV have been reported in children with T2DM as well. Faulkner et al (2003) reported worse autonomic function in youth with T2DM compared to those with type 1 diabetes, which may be partially attributed to the concomitant obesity and lower levels of fitness seen in those with T2DM.

Autonomic neuropathy that occurs in diabetes is neuronal degeneration of sympathetic and parasympathetic nerve fibers and can manifest early in the development of diabetes, but it is often difficult to detect during this subtle phase (Varechova, Durdik, Cervenkova, Ciljakova, Banovcin, \& Hanacek, 2007). It is recognized that the pathway to T2DM involves initial insulin resistance, then IGT, and finally T2DM. While Singh et al (2000) detected poorer autonomic function in the presence of IGT, numerous co-variates, including BMI, contributed to these lower values, which could be partially attributed to greater insulin resistance that is associated with obesity. Severity of insulin resistance is associated with increasing severity of obesity (McLaughlin, Allison, Abbasi, Lamendola, 
\& Reaven, 2004), and greater insulin resistance is associated with more severe impairment of HRV (Bekezin, Kozlova, Kozlova, \& Igolkina, 2008). Thus the decreased HRV seen in obese youth may partially be attributed to insulin resistance. Whether IGT in conjunction with obesity provides an additive effect on autonomic dysfunction in youth has yet to be elucidated.

\section{Glucose Intolerance, Obesity, and QT Interval Duration}

There is a paucity of studies examining QT Interval duration and glucose intolerance. Studies have shown that the occurrence of diabetes is also associated with an increased prevalence of prolonged QT Interval duration (Brown, Giles, Greenlund, \& Croft, 2001; Girola, Enrini, Garbetta, Tufano, \& Cariezel, 2001). A recent study found that approximately $30 \%$ of obese individuals with IGT have prolonged QT Interval (Poirier, Giles, Bray, Hong, Stern, Pi-Sunyer, et al., 2006). However, information on QT Interval duration and glucose intolerance in youth is lacking.

\section{Glucose Intolerance, Obesity, and Left Ventricular Hypertrophy}

Cardiac diastolic dysfunction may be an early complication of IGT with the mechanism of its development similar to that seen in diabetes (Fujita, Asanuma, Kim, Liao, Hirata, Tsukamoto, et al., 2007). In diabetes, hyperglycemia produces advanced glycation end products that form stable and irreversible cross-links with collagen polymers in myocardial and arterial walls, decreasing myocardial compensation and leading to LVH (Fujita et al., 2007). Adult findings have even shown that LVH increased with increasing glucose intolerance (Lundblad \& Eliasson, 2003) and positively correlated with BMI, age, and blood pressure, as well as fasting blood glucose levels (Ebinc, Ebinc, Ozkurt, Dogru, \& Yilmaz, 2006). Even after adjusting for these covariates, women with deteriorating glucose status had increases in left ventricular mass (Henry, Kamp, Kostense, Spijkerman, Dekker, van Eijck, et al., 2004). These findings in adults support the proposition that diabetes and IGT are independent risk factors for LVH (Fujita et al., 2007). Few studies have examined the relationship of LVH with glucose intolerance in children. Recently, Khan and colleagues (Khan, Kerr, Ross, Newton, \& Belch, 2006) found that children $(n=21)$ with even mild glucose intolerance exhibited arterial stiffening. Within the glucose intolerance group, BMI, BP, and left ventricular enlargement positively associated (Khan et al, 2006). Additional studies examining the relationship between glucose intolerance and LVH in youth are needed.

\section{Summary of Glucose Intolerance, Autonomic Dysfunction, and Obesity}

Research indicates that diabetes contributes to autonomic dysfunction and that autonomic alternations precede the development of diabetes. Obesity, insulin resistance, and mild elevations in glucose levels all contribute to autonomic alternations. Adult findings support the relationship between diabetes, LVH, prolonged QT Interval, and 
diminished HRV. Findings suggest that glucose intolerance is associated with prolonged QT Interval in adults. The relationship of glucose intolerance to LVH appears to be modulated by age, BMI, and blood pressure. Studies examining the effect of glucose intolerance on HRV have yielded equivocal results. There is a paucity of information regarding the relationship of IGT to autonomic function in children.

\section{Summary of Review of Literature}

Childhood obesity is linked to the development of T2DM and cardiovascular risk factors, including hypertension. Researchers have suggested that current screening recommendation for obese youth underestimate risk (Velasquez-Mieyer et al., 2007). Examination of additional cardiac risk factors, including decreased HRV, QTc prolongation, and elevated electrographic measures of $\mathrm{LVH}$, which are modulated by autonomic function, may aid in identifying obese youth at increased risk for these obesity-associated co-morbidities.

There is a paucity of research examining HRV, QTc duration, and LVH in obese youth and the relationship of glucose intolerance to these measures. Research findings suggest that autonomic alternations occur prior to the development of diabetes, with even mild elevations in glucose levels contributing to deterioration in autonomic function. Adult studies support the relationship of diabetes and IGT to the development of LVH and prolonged QTc. However, age, BMI, and BP are co-variants affecting the strength of the relationships. Mild, non-significant decreases in HRV have been reported in conjunction with IGT.

Obesity and hypertension, even mild untreated hypertension, are associated with increased risks for LVH and QT prolongation. Linkages between HRV and LVH have not been elucidated in adolescents. However, adult studies suggest that lower HRV measures of parasympathetic function and circadian fluctuation are associated with longer QT Intervals. Obesity is associated with lower HRV measures of sympathetic and parasympathetic function, with duration of obesity affecting relationships between obesity and sympathetic function. Further examination of these factors in overweight and obese adolescents is vital, given the linkage of impaired autonomic function to sudden cardiac death.

Studies suggest that blacks have a higher prevalence of LVH and greater disease burden. Contradictory findings on racial differences in HRV measures and QT Interval duration have been reported; thus further investigation in this area is warranted. 


\section{CHAPTER 3. METHODS}

This study was undertaken to explore relationships between cardiac risk factors of HRV, QTc duration, and electrical voltage criteria for LVH to BMI, RBMI, and blood pressure measures in overweight-obese adolescents. Additionally, this study examined the effects of glucose tolerance, hypertension, and race on HRV, QTc Interval duration, and electrical voltage measures for LVH in this population. The methodology section will provide a description of the study design, setting, sample, instruments, procedures, statistical analysis used to address aims and hypotheses in this study. A description of the approaches used to ensure the protection of human subjects is also provided.

\section{Research Design}

The study design was a cross-sectional, correlational secondary analysis of data. Data were obtained from overweight-obese adolescents age $11-18$ years $(\mathrm{N}=128)$. The overweight-obese youth that participated in this study were part of a larger study designed to investigate potential racial differences associated with IGT in overweightobese youth. The secondary correlational study design was used to study HRV, QTc Interval duration, and electrical voltage measures for LVH differences between adolescent groups with regards to glucose tolerance, hypertension, and race. Descriptive statistics were used to examine the sample characteristics. Through the use of correlation, the researcher was able to understand the relationship between HRV, QTc duration, and electrical voltage measures for LVH in relation to BMI, RBMI, and blood pressure measures. Independent samples t-tests were used to compare glucose tolerance, hypertension, and race in overweight-obese adolescents for cardiovascular risk factors of HRV, QTc duration, and electrical voltage measures for LVH.

\section{Sample and Setting}

The initial sample was recruited from a large metropolitan city in the mid-south region of the United States. A total of 188 charts were reviewed and from the original sample $(\mathrm{N}=128)$ overweight-obese youth who were aged 11-18 years were included in the study sample. Participants were included in this study that had completed data and analyzable ECG at rest and 24-hour Holter monitor recordings. Electrocardiograms and 24-hour Holter recordings that could not be accurately measured and interpreted were excluded, due to the inability to measure accurately and interpret HRV, QTc duration, and electrical voltage for LVH based upon study criteria in this sample of overweightobese youth. 


\section{Inclusion Criteria}

Participants included in the original study were either black or white youth ranging from 11-18 years of age who were overweight or obese. They had no previous diagnosis of diabetes, nor were they taking medications that could affect glucose metabolism or autonomic function. Parents and/or legal guardians signed informed consent and assent was provided by the youth.

For this secondary data analysis, additional inclusion criteria included:

- Age 11-18 years.

- Anthropometrics data available for analysis.

- Analyzable 12-lead electrocardiogram.

- 24-hour Holter recordings, with at least 18 hours of analyzable data available for interpretation.

- Fasting glucose and 2-hour post load values from the oral glucose tolerance test or mixed meal tolerance test available.

\section{Exclusion Criteria}

Exclusion criteria for the current study included:

- Participants younger than 11 or older than 18 years of age at the time the data were collected for the original study.

- Participants that had incomplete data of any of the following measures: anthropometrics, 24-hour Holter monitor, 12-lead electrocardiogram, or oral glucose/mixed meal tolerance test.

- Electrocardiogram or Holter recordings unable to be accurately measured and analyzed according to study criteria.

- Individuals diagnosed with diabetes during the original study.

\section{Sample Description}

The sample consisted of overweight-obese youth age 11-18 years $(\mathrm{N}=128)$. Of the participants included in this study, 51 were whites $(39.8 \%)$ and 77 were black $(60.2 \%)$. The average age of the sample was 14.32 years, with $63.3 \%$ female and $36.7 \%$ male. Six $(4.7 \%)$ were overweight and $122(95.3 \%)$ were obese. Thirty-six $(28.1 \%)$ of participants were classified as having IGT, and ninety-two $(71.9 \%)$ were classified as having normal glucose tolerance. 


\section{Instrumentation}

\section{Body Mass Index and Relative Body Mass Index}

Calculation of BMI was obtained from measurements of height and weight obtained from each participant. During the original study, height was measured on participants without shoes, and weight was measured using a calibrated scale without shoes and excessive clothing. Body mass index was used to classify youth as overweight or obese in $\mathrm{kg} / \mathrm{m}^{2}$ according to age and gender percentiles. Relative body mass index was used to determine severity of obesity and was calculated using the following equation: $(\mathrm{RBMI})\left[\mathrm{BMI} / \mathrm{BMI}^{50 \text { th }}\right.$ percentile for age and sex * 100)].

\section{Oral Glucose and Mixed Meal Tolerance Test}

Glucose tolerance status was determined from data collected during the original study from the 2-hour oral glucose tolerance test or mixed meal tolerance test. The most common method for determining IGT in adolescents is the oral glucose tolerance test (OGTT) (American Diabetes Association, 2008). During the OGTT, dextrose [(1.75 grams $/ \mathrm{kg}$ ) (maximum 75 grams)] is ingested orally and blood samples were obtained prior to administration of dextrose at 30, 60, 90, and 120 minutes (Barker, McFann, \& Orban, 2007). Another method commonly used is the mixed meal tolerance test (MMTT). During the MMTT fasting, subjects ingest a liquid meal and over 2-4 hours Cpeptide levels are measured at timed Intervals (Greenbaum, Mandrup-Poulsen, McGee, Battelino, Haastert, Ludvigsson, et al., 2008). Both tests measure "insulin action, B-cell function, and the rate of meal glucose appearance" (Dalla Man, Campioni, Polonsky, Basu, Rizza, Toffolo, et al., 2005, p\#. 3265). Findings have also indicated a significant correlation between the MMTT and the OGTT (Marena, Montegrosso, De Michieli, Pisu, \& Pagano, 1992).

Following a 10-hour overnight fast, a 2-hour OGTT or MMTT was performed. For completion of the OGTT, one gram of dextrose $/ \mathrm{kg}$ of body weight up to 75 grams was consumed, and blood samples were obtained at 0,15, 30, 60, 90, and 120 minutes during the original study. For the MMTT a liquid meal was ingested (Sustacal/Boost) (6 $\mathrm{kcal} / \mathrm{kg}$, body weight, max $360 \mathrm{kcal}$ ) and blood samples were obtained at $0,15,30,60,90$ and 120 minutes during the original study. Impaired glucose tolerance was determined using the American Diabetes Association 2008 guidelines. Impaired glucose tolerance was determined if participants had a fasting glucose level of $100-126 \mathrm{mg} / \mathrm{dl}$ or a 2-hour plasma glucose level between 140-200 mg/dl.

\section{Systolic/Diastolic Blood Pressure}

A resting blood pressure was obtained with a sphygmomanometer and appropriate size cuff. Normative blood pressure tables developed by the National High Blood 
Pressure Education Program Working Group on High Blood Pressure in Children and Adolescents were utilized for single blood pressure readings rather than multiple readings. These guidelines have recently incorporated the pre-hypertensive category (McNiece et al., 2007). A SBP or DBP $\geq 95^{\text {th }}$ percentile was considered hypertension, Pre-hypertension was categorized as having a systolic/diastolic blood pressure $\geq 90^{\text {th }}$ but less than the $95^{\text {th }}$ percentile, and non-hypertensive is a systolic/diastolic blood pressure $<$ $90^{\text {th }}$ percentile for age, height, and sex (McNiece et al., 2007). Pre-hypertension is a fairly new classification for blood pressure (American Heart Association, 2009), but studies conducted have identified that pre-hypertension is linked to increased cardiovascular risk (Qureshi, Suri, Kirmani, Divani, \& Mohammad, 2005; American Heart Association, 2009). Pre-hypertensive or hypertensive youth have an increased incidence of alterations in cardiac structure, which includes the presence of $\mathrm{LVH}$, compared to youth with normal blood pressures. This suggests that pre-hypertension has a profound effect on cardiovascular risk, similar to that seen in hypertension. Therefore, pre-hypertensive adolescents were grouped with hypertensive adolescents to form the elevated blood pressure group and subject groups consisted of those identified to have elevated blood pressure or as non-hypertensive.

\section{Ambulatory Electrocardiogram Analysis and Editing}

Marquette Electronics version 5.8 Ambulatory Electrocardiogram Analysis and Editing System was utilized for editing and analysis of Holter recorded data for HRV. During the initial study, subjects participated in normal activities and were advised not to expose the Holter monitor to water while documenting sleep, exercise, or unusual stress. Following the conclusion of the 24-hour period, subjects removed the Holter monitor. Recordings were scanned into the Multi-parameter Arrhythmia Review Station (MARS) PC Analysis and Editing system (GE Marquette Medical Systems, Milwaukee, WI, USA) version 5.8, and QRS complexes were digitally processed and assigned a template for manual validation and over reading. Following validation, HRV was performed using the computerized system according to the manufacturer settings.

The power spectral density technique was used in this study to separate frequency waveforms into low (0.04-0.15 Hertz), high (0.15-0.40 Hertz), and total frequency (0.1$1.0 \mathrm{Hertz}$ ) components. The low frequency component is representative of sympathetic and parasympathetic function. The high frequency component reflects parasympathetic function, and the total frequency component reflects R-R interval variability. 24-hour measures of high frequency components and time domain measures of SDNN were utilized in the analysis of HRV data, with each recording containing at least 18 hours of analyzable data.

\section{2-lead Electrocardiogram}

A 12-lead electrocardiogram was conducted on all participants at rest during the

original study to determine QTc duration and Cornell voltage measures for LVH. A 
researcher trained in electrocardiogram rhythm analysis manually measured the available data, and measures were initially reviewed and validated by a skilled Pediatric Cardiologist, to ensure accuracy and consistency. The 12-lead electrocardiogram was conducted at a standard paper speed of $25 \mathrm{~mm} / \mathrm{sec}$.

The QT Interval was measured from the beginning of the QRS complex to the end deflection of the T wave. By dividing the square root of the preceding R-R interval of each QT Interval in the tracing, the three distinct, corrected QT Intervals (QTc) were determined according to Bazett's formula, correcting for variations in heart rate. After the QT Interval and the preceding RR interval were examined in three consecutive waveforms and corrected individually in lead II of the 12-lead electrocardiogram, the average of the three QTc calculations were used to determine the QTc within the electrocardiogram tracing for data purposes. The QTc Interval was considered prolonged if $>0.425 \mathrm{sec}$ in adolescent males and females aged 11-18 years.

Left ventricular hypertrophy was determined in the overweight and obese youth using the Cornell Voltage Criteria by measuring the S wave in lead V3 + R wave in lead aVL. In obese individuals, electrical forces within the heart become more posterior, and the $\mathrm{S}_{\mathrm{V} 3}$ is the most representative voltage for evaluating posterior electrical forces (Eckel, 2003). When LVH is present in obese individuals, the heart is shifted more horizontally in the chest cavity, which explicates the importance of the $\mathrm{R}_{\mathrm{aVL}}$ (Eckel, 2003). These measurements are for the Cornell criteria.

The $\mathrm{R}$ wave was measured as the first positive deflection in the QRS complex, following the $\mathrm{Q}$ wave and arising from ventricular activation. The $\mathrm{S}$ wave was measured as the negative deflection following the $\mathrm{R}$ wave in the QRS complex. The normal $\mathrm{S}$ wave in lead V3 and R wave in aVL have yet to be identified for adolescents for use when overweight-obesity is present, but according to adult criteria in obese adults LVH is considered to be present in males if $\mathrm{S}_{\mathrm{V} 3}+\mathrm{R}_{\mathrm{aVL}}$ is $>2.8 \mathrm{mV}$ and in females $>2.0 \mathrm{mV}$. Cornell voltage criteria have not yet been used in overweight-obese youth, and adult criteria were used to determine the presence LVH in overweight-obese youth (see Table 3-1).

\section{Procedures}

Institutional Review Board (IRB) approval was obtained from The University of Tennessee Health Science Center to conduct this study. In addition, prior written consent was obtained from parents or legal guardians and assent from youth prior to enrollment in the original study.

\section{Selection of Participants}

Based on the information provided in the larger study $(\mathrm{N}=128)$, participants were selected. Consent forms from the larger study were reviewed. Also, the principle 
Table 3-1. Variables and Measurements.

\begin{tabular}{|c|c|}
\hline Variable & Measurement \\
\hline Demographic Data & Age, Gender, \& Race. \\
\hline Overweight-Obese & $\begin{array}{l}\text { Body mass index } \geq 85^{\text {th }} \text { overweight or } \geq 95 \text { th obese for age } \\
\text { and gender percentiles. }\end{array}$ \\
\hline Severity of Obesity & $\begin{array}{l}\text { Relative body mass index } \\
\text { BMI / }\left(\mathrm{BMI}^{50 t \mathrm{th}} \text { percentile for age and sex } * 100\right) \text {. }\end{array}$ \\
\hline Glucose Tolerance & $\begin{array}{l}\text { Oral glucose or mixed meal tolerance test, IGT = FG 100- } \\
126 \mathrm{mg} / \mathrm{dl} \text { or } 2 \text {-hour post load between } 140-200 \mathrm{mg} / \mathrm{dl} \text {. }\end{array}$ \\
\hline Elevated BP & $\begin{array}{l}\text { Systolic and diastolic BP measures } \geq 90^{\text {th }} \text { percentile for age } \\
\text { and gender }=\text { elevated BP. }\end{array}$ \\
\hline Heart Rate Variability & $\begin{array}{l}\text { 24-hour measures of SDNN (circadian fluctuation) and high } \\
\text { frequency (parasympathetic function). }\end{array}$ \\
\hline QT Interval duration & 12-Lead ECG $(\mathrm{QTc}=\mathrm{QT} / \sqrt{ } \mathrm{RR})>0.425 \mathrm{sec}=$ prolonged. \\
\hline $\begin{array}{l}\text { Cornell Voltage for } \\
\text { LVH }\end{array}$ & $\begin{array}{l}\text { 12-Lead ECG }(\mathrm{S} \text { wave in } \mathrm{V} 3+\mathrm{R} \text { wave in } \mathrm{aVL})>2.8 \mathrm{mV} \text { in } \\
\text { males or }>2.0 \mathrm{mV} \text { females }=\mathrm{LVH} \text {. }\end{array}$ \\
\hline
\end{tabular}

Note. IGT = Impaired Glucose Tolerance; FG = Fasting Glucose; BP = Blood Pressure; $\mathrm{ECG}=$ Electrocardiogram; LVH = Left Ventricular Hypertrophy. 
investigator in the current study was given access to Holter recording data through the MARS PC Workstation for HRV analysis, 12-lead electrocardiogram reports for analysis of QTc duration and $\mathrm{LVH}$, and also access to de-identified data from the larger study, including oral glucose tolerance status and anthropometrics for calculation of BMI. Holter recording analysis and electrocardiogram analysis data were matched to the initial subject using the code assigned to the participant. The current study included $(\mathrm{N}=128)$ overweight-obese youth that did not have missing or incomplete data. Data collection for the larger study occurred in a large metropolitan city in the mid-south region of the United States.

\section{Data Analysis}

Data analysis was conducted using Statistical Software for the Social Sciences (SPSS) software version 15.0. Data were entered into an Excel spreadsheet; de-identified and codes were used to maintain confidentiality and anonymity. The data were subsequently imported to SPSS v. 15.0 for data analysis. Frequency distributions were obtained for categorical data such as race, gender, age, hypertensive status, and glucose tolerance. Descriptive statistics were performed to describe and characterize the sample of overweight-obese adolescents. Pearsons Correlation Coefficients were estimated to examine relationships between variables. Statistical tests included independent samples $\mathrm{t}$-tests and chi-square analysis. The a priori significance level was set at 0.05 for all research aims.

Following a description and characterization of overweight-obese adolescents aims of this study:

(1) Examined the relationship between HRV, QTc Interval duration, and electrical voltage measures for LVH to BMI, RBMI, and systolic/diastolic blood pressure measures in overweight-obese adolescents.

Hypothesis: It was hypothesized that BMI, RBMI, and increased systolic/diastolic blood pressure measures would be associated with lower HRV, more prolonged QTc duration, and higher measures of electrical voltage for LVH.

To address this aim, Pearson's Product Moment Correlation Coefficients were used to examine relationships between the variables.

(2) Compared HRV, QTc Interval duration, and electrical voltage measures for LVH in overweight-obese adolescents with and without IGT.

Hypotheses: Overweight-obese adolescents with IGT would exhibit lower HRV, more prolonged QTc Interval, and higher electrical voltage measures for LVH compared to overweight-obese adolescents with normal glucose tolerance. 
To address aim two; Levene's test of homogeneity of variance was used to meet the assumption of equal variances. For variables that met the condition of equal variances, independent samples t-test was used to determine differences in overweight-obese adolescents with and without IGT.

(3) Compared HRV, QTc Interval duration, and electrical voltage measures for LVH in overweight-obese adolescents with elevated blood pressure and nonhypertension.

Hypotheses: Overweight-obese adolescents with elevated blood pressure would exhibit lower HRV, more prolonged QTc Interval, and higher electrical voltage measures for LVH compared to overweight-obese adolescents with nonhypertension.

To address aim three Levene's test of homogeneity of variance was used to meet the assumption of equal variances. For variables that met the condition of equal variances, independent sample t-test was used to determine differences in overweight-obese adolescents with elevated blood pressure and non-hypertension. Chi-square analysis was used to evaluate differences in frequency of elevated blood pressure distributions between glucose tolerance groups.

(4) Compared HRV, QTc Interval, and electrical voltage measures for LVH in black and white overweight-obese adolescents.

Hypotheses: Black overweight-obese adolescents will display lower HRV, more prolonged QTc Interval, and higher electrical voltage measures for LVH than their white peers.

To address aim four; Levene's test of homogeneity of variance was used to meet the assumption of equal variances. For variables that met the condition of equal variances, independent samples t-test was used to determine differences in black vs. white overweight-obese adolescents in relation to HRV, QTe duration, and electrical voltage measurements for LVH. Chi-square analysis was used to evaluate differences in frequency distributions between racial groups for glucose tolerance.

\section{Protection of Human Subjects}

The original and current study received Institutional Review Board approval from the University. Written and verbal consent and assent was received from parents/legal guardians and participants respectively during the original study, and the principle investigator maintained each participant's confidentiality and anonymity. Files containing participant data from the original study were kept in a locked file cabinet in a health clinic and only IRB approved study personnel were allowed access, and the data were deidentified with codes, and the codes were used to match Holter and electrocardiograms to 
the appropriate participant. Risks to study participants that were identified in the original study included weakness and fatigue due to the fasting state necessary for the OGTT and MMTT. In addition venipuncture during the OGTT and MMTT could have caused pain, excessive bleeding, or increased risk for infection at the insertion site due to a break in the skin's natural integrity. The sites of electrode placement for the electrocardiogram or Holter monitor could also lead to skin irritation. Although minimal risks were involved in the initial study they were outweighed by the expected benefits gained as a result of conducting the study. During the current study of previously collected data there were no risks involved, with the exception of the risk for a breach in patient confidentiality. Therefore, all data were kept confidential and coded to maintain the participants' anonymity. 


\title{
CHAPTER 4. RESULTS
}

\section{Introduction}

The purpose of this study was to examine relationships for HRV, QTc duration, and electrical voltage measures for LVH to BMI, RBMI, and blood pressure measures in overweight-obese adolescents. In addition, this study sought to determine the effects of glucose tolerance, hypertension, and race on HRV, QTc Interval duration, and electrical voltage criteria for LVH in overweight-obese adolescents. The results from this study may provide additional risk stratification in adolescents by identifying whether overweight-obesity with concomitant glucose intolerance, hypertension, and/or race adversely affects HRV, QTc duration, and/or electrical voltage measures for LVH, compounding cardiovascular risks. This chapter provides a description of sample characteristics in addition to an analysis of results to research aims.

\section{Description of the Sample}

The sample consisted of $(\mathrm{N}=128)$ overweight-obese adolescents age 11-18 years that were initially part of a larger study. All of the study participants were overweightobese according to the Centers for Disease Control, based on age, height, and gender percentiles. Study participants had primarily been recruited from an obesity-diabetes specialty clinic located in a large metropolitan city within the mid-south region of the United States. This clinic serves as a referral clinic for adolescents within a 250-mile radius. Additionally, participants were recruited through flyers at area family practice clinics. A total of 188 charts were reviewed to determine eligibility for this secondary data analysis. Of these 188 records, 128 met all inclusion criteria and had complete data sets available for analysis. Participants included in this study consisted of 51 whites $(39.8 \%)$ and 77 blacks $(60.2 \%)$, of which the majority was female (63.3\%). Six adolescents (4.7\%) were overweight and 122 (95.3\%) were obese. Table 4-1 summarizes the descriptive characteristics of the entire sample.

Glucose tolerance and blood pressure status were obtained for the total group. In addition, cardiac risk factors of HRV, QTc duration, and electrocardiographic voltage measures for LVH (Cornell Criteria) were obtained. Elevations in systolic blood pressure were more common than elevations in diastolic blood pressure (51.5\% vs. $0.09 \%)$, with diastolic hypertension always occurring in the presence of systolic hypertension. Table 42 summarizes the mean values for each of the variables.

\begin{abstract}
Aim One
Aim one examined relationships between HRV, QTc Interval duration, and Cornell electrical voltage measures for LVH to BMI, RBMI, and systolic/diastolic blood
\end{abstract}


Table 4-1. Characteristics of Study Participants.

\begin{tabular}{lc}
\hline \multicolumn{1}{c}{ Characteristic } & $\begin{array}{c}\text { Total Group } \\
(\mathrm{N}=128)\end{array}$ \\
\hline Age (years; mean $\pm \mathrm{SD})$ & $14.32 \pm 1.91$ \\
Body Mass Index & $37.18 \pm 7.40$ \\
Relative Body Mass Index & $188.22 \pm 34.76$ \\
Race (\% Black) & 60.1 \\
Gender (\% F) & 63.2 \\
\hline
\end{tabular}

Note. $\mathrm{F}=$ Female. 
Table 4-2. Cardiac Risks in Overweight-Obese Adolescents.

\begin{tabular}{lc}
\hline \multicolumn{1}{c}{ Characteristic } & Total Group \\
\hline Systolic BP (mm/Hg; mean $\pm \mathrm{SD})$ & $123.63 \pm 13.31$ \\
Diastolic BP (mm/Hg; mean $\pm \mathrm{SD})$ & $69.47 \pm 8.36$ \\
Elevated BP $(\%)$ & 51.5 \\
IGT $(\%)$ & 28.1 \\
High Frequency (ms ${ }^{2}$; mean $\left.\pm \mathrm{SD}\right)$ & $6.23 \pm 1.86$ \\
SDNN (ms; mean \pm SD) & $138.94 \pm 39.67$ \\
Average QTc duration (sec; mean \pm SD) & $0.408 \pm 0.350$ \\
QTc Prolonged (\%) & 34.3 \\
$\begin{array}{l}\text { Cornell Voltage Criteria } \\
\text { (mV; mean } \pm \text { SD) }\end{array}$ & $0.86 \pm 0.35$ \\
\hline
\end{tabular}

Note. $\mathrm{BP}=$ Blood Pressure; IGT = Impaired Glucose Tolerance; SDNN = Standard deviation of all normal RR intervals. 
pressure measures in overweight-obese adolescents. Specifically it is also hypothesized that BMI, RBMI, and increased systolic/diastolic blood pressure measures will be associated with lower high frequency and SDNN measures of HRV, more prolonged QTc duration, and higher measures of electrical voltage for LVH. Pearson's Product Moment Correlation Coefficients were used to examine relationships between the variables, with an alpha level of 0.05 set for statistical significance.

The relationships between HRV, QTc Interval duration, and electrical voltage measures for LVH to BMI, RBMI, and blood pressure were explored using correlational analysis. BMI was not significantly correlated with high frequency or SDNN measures of HRV, QTc Interval duration, or Cornell voltage measures for LVH. Relative body mass index was not significantly correlated with high frequency or SDNN (circadian fluctuation) HRV measures, QTc Interval duration, or Cornell voltage measures for LVH. Systolic blood pressure measures modestly correlated with Cornell voltage measures $(\mathrm{r}=$ $0.231, \mathrm{p}=0.009$ ) but not with high frequency, SDNN, or QTc Interval duration. Diastolic blood pressure measures did not correlate with high frequency or SDNN measures of HRV, QTc Interval duration, or Cornell voltage measures.

In summary, higher systolic blood pressure measures were modestly correlated to Cornell voltage measures for LVH. Table 4-3 displays the Pearson Product Moment Correlational Coefficients between the cardiac risk factors.

\begin{abstract}
Aim Two
Aim two examined the effect of glucose tolerance on HRV, QTc Interval duration, and measures of electrical voltage for LVH in overweight-obese adolescents. Subjects were grouped, based upon glucose tolerance status, as either having IGT (fasting blood glucose $\geq 100$ and $<126 \mathrm{mg} / \mathrm{dl}$ or 2 -hr post-load glucose $\geq 140$ and $<200 \mathrm{mg} / \mathrm{dl}$ ) or normal glucose tolerance (fasting glucose $<100 \mathrm{mg} / \mathrm{dl}$ or 2-hr post-prandial glucose $<$ $140 \mathrm{mg} / \mathrm{dl}$ ). Chi-square analysis and independent samples t-tests were performed to examine whether the characteristics of the two groups differed. The two groups were similar in age, gender, race, and severity of obesity ( $p=$ NS for all comparisons; see Table 4-4). Independent samples t-tests were used to compare HRV measures, QTc duration, and Cornell voltage for LVH between glucose tolerance groups. Differences in the frequency of elevated blood pressure between the glucose tolerance groups were examined using Chi-square analysis. An alpha level of 0.05 was significance a priori.

There were no significant differences in $\operatorname{HRV}(\mathrm{HF}, \mathrm{p}=0.25$; SDNN, $\mathrm{p}=0.108)$, QTc duration $(\mathrm{p}=0.59)$, or Cornell voltage $(\mathrm{p}=0.33)$ between the IGT and NGT groups (see Table 4-5). In addition the IGT group had a slightly higher frequency of elevated blood pressure than the NGT group, though not statistically significant $(64 \%$ vs. $47 \%, \chi=$ $3.047, \mathrm{p}=0.08)$.
\end{abstract}


Table 4-3. Correlations between Cardiac Risks in Overweight-Obese Adolescents.

\begin{tabular}{lcccc}
\hline \multicolumn{1}{c}{ Variable } & HF & SDNN & QTc & $\begin{array}{c}\text { Cornell } \\
\text { Voltage }\end{array}$ \\
& & & & \\
\hline & & & & \\
BMI & & & & 0.004 \\
$\mathrm{r}=$ & 0.077 & -0.075 & 0.065 & 0.968 \\
$\mathrm{p}=$ & 0.385 & 0.400 & 0.465 & \\
$\mathrm{RBMI}$ & & & & \\
$\mathrm{r}=$ & & & & 0.026 \\
$\mathrm{p}=$ & -0.028 & -0.121 & 0.087 & 0.767 \\
$\mathrm{SBP}$ & 0.750 & 0.173 & 0.331 & \\
$\mathrm{r}=$ & & & & 0.231 \\
$\mathrm{p}=$ & 0.056 & 0.080 & 0.061 & \\
& 0.532 & 0.371 & 0.495 & $0.009 *$ \\
$\mathrm{DBP}$ & & & & \\
$\mathrm{r}=$ & & & & 0.031 \\
$\mathrm{p}=$ & 0.078 & -0.136 & 0.171 & \\
& 0.380 & 0.125 & 0.053 & \\
\hline
\end{tabular}

Note. $\mathrm{HF}=$ High Frequency; SDNN = Standard Deviation of all normal RR intervals; Cornell Voltage $=\mathrm{S}$ wave in $\mathrm{V} 3+\mathrm{R}$ wave in AvL; $\mathrm{BMI}=$ Body Mass Index; $\mathrm{RBMI}=$ Relative Body Mass Index; SBP $=$ Systolic Blood Pressure; DBP = Diastolic Blood Pressure; $* \mathrm{p} \leq 0.05$. 
Table 4-4. Characteristics of Study Participants Based on Glucose Status.

\begin{tabular}{lcc}
\multicolumn{1}{c}{ Variable } & $\begin{array}{c}\text { IGT } \\
(\mathrm{n}=36)\end{array}$ & $\begin{array}{c}\text { NGT } \\
(\mathrm{n}=92)\end{array}$ \\
\hline Age (years; mean \pm SD) & $14.11 \pm 1.89$ & $14.40 \pm 1.93$ \\
Body Mass Index & $36.62 \pm 6.47$ & $37.40 \pm 7.76$ \\
Relative Body Mass Index & $186.33 \pm 29.51$ & $188.95 \pm 36.73$ \\
Race (\% Black) & 61.1 & 59.7 \\
Gender (\% F) & 63.8 & 63.0 \\
\hline
\end{tabular}

Note. IGT $=$ Impaired Glucose Tolerance; NGT $=$ Normal Glucose Tolerance $; \mathrm{F}=$ Female; $\mathrm{P}=$ NS between groups for all measures. 
Table 4-5. Cardiac Risks in Study Participants Based on Glucose Status.

\begin{tabular}{|c|c|c|}
\hline Variable & $\begin{array}{c}\text { IGT } \\
(\mathrm{n}=36)\end{array}$ & $\begin{array}{c}\text { NGT } \\
(n=92)\end{array}$ \\
\hline Systolic BP $(\mathrm{mm} / \mathrm{Hg} ;$ mean $\pm \mathrm{SD})$ & $125.47 \pm 14.09$ & $122.90 \pm 12.99$ \\
\hline Diastolic BP $(\mathrm{mm} / \mathrm{Hg} ;$ mean $\pm \mathrm{SD})$ & $70.06 \pm 7.19$ & $69.24 \pm 8.80$ \\
\hline Elevated BP (\%) & 63.8 & 46.7 \\
\hline High Frequency $\left(\mathrm{ms}^{2} ;\right.$ mean $\left.\pm \mathrm{SD}\right)$ & $6.60 \pm 4.09$ & $6.08 \pm 0.90$ \\
\hline $\mathrm{SDNN}(\mathrm{ms} ;$ mean $\pm \mathrm{SD})$ & $130.75 \pm 32.94$ & $142.14 \pm 41.73$ \\
\hline $\begin{array}{l}\text { Average QTc duration (sec; mean } \pm \\
\text { SD) }\end{array}$ & $0.411 \pm 0.029$ & $0.407 \pm 0.036$ \\
\hline QTc Prolonged & 38.8 & 32.6 \\
\hline $\begin{array}{l}\text { Cornell Voltage Criteria } \\
(\mathrm{mV} ; \text { mean } \pm \mathrm{SD})\end{array}$ & $0.91 \pm 0.33$ & $0.84 \pm 0.36$ \\
\hline
\end{tabular}

Note. IGT $=$ Impaired Glucose Tolerance; NGT $=$ Normal Glucose Tolerance; $\mathrm{BP}=$ Blood Pressure; SDNN = Standard deviation of all normal RR intervals; $\mathrm{P}=\mathrm{NS}$ between groups for all measures. 


\begin{abstract}
Aim Three
Aim three examined differences in HRV, QTc Interval duration, and Cornell voltage measures for LVH in overweight-obese youth with and without elevated blood pressure. Subjects were initially grouped based upon blood pressure status as prehypertensive, hypertensive, or non-hypertensive. Frequency tables were prepared which indicated $39.8 \%$ hypertensive, $11.7 \%$ pre-hypertensive, and $48.4 \%$ non-hypertensive. Studies suggest that cardiovascular risk associated with pre-hypertension is similar to that identified in hypertension (American Heart Association, 2009; Qureshi et al., 2005), therefore, pre-hypertensive and hypertensive subjects were grouped to form the elevated blood pressure category. Independent samples t-tests were used to compare elevated blood pressure and non-hypertensive groups based upon HRV measures, QTc duration, and Cornell voltage measures (see Table 4-6).
\end{abstract}

There was no significant difference in parasympathetic function (HF, $p=0.31$ ), SDNN ( $p=0.80)$, and QTc $(p=0.92)$ between the blood pressure groups. Subjects with elevated blood pressure displayed significantly higher measures of Cornell Voltage for LVH $(0.95 \mathrm{mV}$ vs. $0.76 \mathrm{mV}, \mathrm{p}=0.004)$ than those overweight-obese youth with normal blood pressure measures (see Table 4-7).

\begin{abstract}
Aim Four
Minorities experience a considerable disease burden engendered by overweightobesity (Department of Health and Human Services, 2003). Aim 4 examined whether black overweight-obese youth exhibited lower HRV, more prolonged QTc duration, and higher Cornell voltage measures for LVH than their white peers. Subjects were grouped based upon self-reported race as either black or white. Independent samples t-test was used to compare groups for HRV, QTc duration, and Cornell voltage measures for LVH. Chi-square analysis was used to evaluate racial differences in frequency distributions of glucose tolerance (see Table 4-8).
\end{abstract}

There was no significant difference between racial groups for high frequency $(\mathrm{p}=$ $0.106)$, QTc $(p=0.599)$, or Cornell voltage for LVH $(p=0.965)$. Black adolescents had a significantly lower SDNN (circadian fluctuation), than white peers ( $p=0.000$; see Table 4-9). In addition, overweight-obese black adolescents had a similar frequency of IGT as white peers, $(28.57 \%$ vs. $27.45 \%, \chi=0.01, \mathrm{p}=0.890)$. 
Table 4-6. Characteristics of Study Participants Based on Blood Pressure Status.

\begin{tabular}{lcc}
\hline \multicolumn{1}{c}{ Variable } & $\begin{array}{c}\text { Elevated BP } \\
(\mathrm{n}=66)\end{array}$ & $\begin{array}{c}\text { Non-Hypertension } \\
(\mathrm{n}=62)\end{array}$ \\
\hline Age (years; mean $\pm \mathrm{SD})$ & $14.45 \pm 0.21$ & $14.18 \pm 0.26$ \\
Body Mass Index & $38.72 \pm 0.87$ & $35.54 \pm 0.93$ \\
Relative Body Mass Index & $194.88 \pm 3.97$ & $181.12 \pm 4.52$ \\
Race (\% Black) & 60.6 & 70.9 \\
Gender (\% F) & 56.1 & 59.6 \\
\hline
\end{tabular}

Note. $\mathrm{BP}=$ Blood Pressure $; \mathrm{F}=$ Female; $\mathrm{P}=$ NS between groups for all measures. 
Table 4-7. Cardiac Risks in Study Participants Based on Blood Pressure Status.

\begin{tabular}{lcc}
\hline \multicolumn{1}{c}{ Variable } & $\begin{array}{c}\text { Elevated BP } \\
(\mathrm{n}=66)\end{array}$ & $\begin{array}{c}\text { Non-Hypertension } \\
(\mathrm{n}=62)\end{array}$ \\
\hline Systolic BP (mm/Hg; mean $\pm \mathrm{SD})$ & $133.23 \pm 9.40$ & $113.40 \pm 8.26$ \\
Diastolic BP (mm/Hg; mean $\pm \mathrm{SD})$ & $71.91 \pm 8.24$ & $66.87 \pm 7.73$ \\
IGT (\%) & 34.8 & 20.9 \\
High Frequency (ms ${ }^{2}$; mean $\left.\pm \mathrm{SD}\right)$ & $6.42 \pm 3.06$ & $6.01 \pm 0.91$ \\
SDNN (ms; mean \pm SD) & $139.82 \pm 40.30$ & $138.00 \pm 39.28$ \\
Average QTc Duration (sec; mean \pm SD) & $0.408 \pm 0.033$ & $0.408 \pm 0.037$ \\
$\begin{array}{l}\text { QTc Prolonged }(\%) \\
\text { Cornell Voltage Criteria } \\
\text { (mV; mean } \pm \text { SD) }\end{array}$ & 33.3 & 35.4 \\
\hline
\end{tabular}

Note. $\mathrm{BP}=$ Blood Pressure; IGT = Impaired Glucose Tolerance; SDNN = Standard deviation of all normal RR intervals; $* \mathrm{p} \leq 0.05$. 
Table 4-8. Characteristics of Study Participants Based on Race.

\begin{tabular}{lcc}
\hline \multicolumn{1}{c}{ Variable } & $\begin{array}{c}\text { Blacks } \\
(\mathrm{n}=77)\end{array}$ & $\begin{array}{c}\text { Whites } \\
(\mathrm{n}=51)\end{array}$ \\
\hline Age (years; mean $\pm \mathrm{SD})$ & $14.22 \pm 1.95$ & $14.77 \pm 1.86$ \\
Body Mass Index & $37.56 \pm 8.06$ & $36.61 \pm 6.32$ \\
Relative Body Mass Index & $190.36 \pm 37.80$ & $184.98 \pm 29.64$ \\
Gender (\% F) & 71.4 & 50.9 \\
\hline
\end{tabular}

Note. $\mathrm{F}=$ Female; $\mathrm{P}=\mathrm{NS}$ between groups for all measures. 
Table 4-9. Cardiac Risks in Study Participants Based on Race.

\begin{tabular}{lcc}
\hline \multicolumn{1}{c}{ Variable } & Blacks & Whites \\
\hline Systolic BP (mm/Hg; mean \pm SD) & $123.65 \pm 14.06$ & $123.59 \pm 12.20$ \\
Diastolic BP (mm/Hg; mean \pm SD) & $70.61 \pm 8.75$ & $67.75 \pm 7.49$ \\
Elevated BP (\%) & 51.9 & 50.9 \\
IGT (\%) & 28.5 & 27.4 \\
High Frequency (ms ${ }^{2}$; mean \pm SD) & $5.96 \pm 0.89$ & $6.63 \pm 3.44$ \\
SDNN (ms; mean \pm SD) & $128.62 \pm 35.16^{*}$ & $154.51 \pm 41.30$ \\
Average QTc duration $(\mathrm{sec} ;$ mean \pm SD) & $0.407 \pm 0.384$ & $0.410 \pm 0.029$ \\
QTc Prolonged (\%) & 32.4 & 37.2 \\
Cornell Voltage Criteria (mV; mean \pm SD) & $0.86 \pm 0.33$ & $0.86 \pm 0.38$ \\
\hline
\end{tabular}

Note. $\mathrm{BP}=$ Blood Pressure; IGT = Impaired Glucose Tolerance; SDNN = Standard deviation of all normal RR intervals; $* \mathrm{p} \leq 0.05$. 


\title{
CHAPTER 5. DISCUSSION, IMPLICATIONS, AND CONCLUSIONS
}

This study investigated the effects of glucose tolerance, hypertension, and race on HRV, QTc Interval duration, and measures of Cornell voltage for LVH in overweightobese adolescents. This chapter presents a discussion of the study findings and explores the relationship of these findings to practice, theory, and other research findings.

The sample consisted of 128 overweight-obese adolescents with an average age of 14.32 years of age. The majority of the participants were obese black females. A high prevalence of pre-diabetes in obese children and adolescents has been reported (Rodbard, 2008), and this study further supports this finding. Twenty-eight percent of overweightobese youth within this study had IGT, which is slightly higher than results noted within the literature that state $25 \%$ of obese youth have IGT (Plourde, 2006). Pletcher and colleagues (2008) reported that in young adults pre-hypertension is more common in blacks than whites. Within our study both black and white youth were just as likely to have elevated blood pressure (50\% vs. 51\%), respectively, in the presence of overweightobesity.

\begin{abstract}
Aim One
Aim one examined the relationship between cardiac risk factors of HRV, QTc Interval duration, and Cornell voltage measures for LVH to BMI, RBMI, and systolic and diastolic blood pressure measures in overweight-obese adolescents.

Study findings indicated BMI, RBMI, and diastolic blood pressure measures did not correlate with HF and SDNN measures of HRV, QTc Interval, or Cornell voltage measures. Systolic blood pressure did not correlate with HF and SDNN measures of HRV and QTc Interval, but was significantly correlated with Cornell voltage measures.

Divergent findings have been reported for HF and SDNN measures of HRV and QT Interval duration when obesity is present. Researchers acknowledge overall HRV measures are not decreased in obese youth (Martini et al., 2001), and further investigations reported obese youth have slightly lower HF measures (Martini et al., 2001), while decreased SDNN is reported in individuals with T2DM (Periaccante et al., 2006). Contrary findings have been reported regarding the relationship of obesity to QT Interval duration in adults. While several studies indicated that obesity might lead to QT prolongation (El Gamal et al., 1995; Poirier et al., 2006), another found no correlation existed between QT duration and BMI (Girola et al., 2001).

Cornell voltage measures within our study did not suggest that LVH was present in any adolescent in this study, based upon the adult standard. An adult standard was used because normative standards in overweight-obese adolescents using Cornell criteria have not yet been established. The lack of variability of Cornell voltage measures in overweight-obese youth and no identified LVH in subjects may have contributed to the
\end{abstract}


lack of correlation identified between BMI, RBMI, and Cornell voltage measures for LVH.

A modest correlation was identified for systolic blood pressure and Cornell voltage measures. This is not surprising because the most common cause of LVH is hypertension (Edhouse et al., 2002) and even mild hypertension in youth is shown to correlate with LVH (Ippisch \& Daniels, 2008). No correlation was identified for systolic and diastolic blood pressure for HRV measures of HF and SDNN, and QTc duration. Literature reports when hypertension is present, SDNN measures of HRV are reduced (Alter et al., 2006) and when mild hypertension is present there may be no difference identified in HRV measures (Franchi et al., 1996). In this group of overweight-obese youth, HF measures and SDNN measures of HRV are not correlated with blood pressure measures. Faulkner and colleagues (2005) reported age and gender variations in HRV measures, and females are reported to have lower HRV values than males. This sample contained slightly more females, which could have influenced study findings.

Prolongation of the QTc Interval has been identified to be associated with hypertension in children (Kocak et al., 1999), but similar to HRV measures it has been reported that no difference in QT duration may present when hypertension is mild (Franchi et al., 1996).

Obesity is associated with cardiac autonomic dysfunction (Gutin, Howe, Johnson, Humphries, Snieder, \& Barbeau, 2005), QTc duration (Poirier et al., 2006), and LVH (Vasan, 2003) in adult subjects. However, overall lack of correlation identified for BMI and RBMI to HRV, QTc duration, and Cornell voltage in this study could be related to the overall marked elevation of BMI and RBMI throughout the entire sample. The inclusion or a more varied weight group and/or healthy weight adolescents would be beneficial for future investigation.

\begin{abstract}
Aim Two
Aim two examined differences between glucose tolerance groups for the dependent variables; HRV, QTc duration, and Cornell voltage criteria for LVH in overweight-obese adolescents. It has been noted that diabetes is linked to diminished HRV (Periaccante et al., 2006), prolonged QTc duration (Vinod Porwal, 2005), and the presence of LVH (Foppa, Duncan, Arnett, Benjamin, Liebson, Manolio, \& Skelton, 2006). Therefore, it was important to investigate if this link also existed for pre-diabetes amongst these variables in overweight-obese adolescents. Although HRV measure of SDNN was slightly decreased, QTc duration slightly prolonged, and Cornell voltage measures for LVH were slightly increased in the impaired glucose tolerant group, these values were not significantly different from the normal glucose tolerant group.

Research in adults suggests a weak relationship between pre-diabetes and HRV measures (Schroeder, Chambless, Liao, Prineas, Evans, Rosamond, et al., 2005), which is consistent with findings from this current study. In adults with T2DM, HRV measures of SDNN are decreased (Periaccante et al., 2006); however, although SDNN is slightly
\end{abstract}


decreased in this sample of overweight-obese adolescents, no statistically significant difference was noted.

In adolescents, a QTc Interval $>0.425 \mathrm{sec}$ is considered prolonged, and in this study $38 \%$ of overweight-obese adolescents with IGT had QTc Interval prolongation. A study in adults report approximately $30 \%$ of obese individuals with IGT have QTc prolongation (Poirier et al., 2006). Similar findings were noted in this study of overweight-obese adolescents; of those adolescents with IGT, 38\% had QTc Interval prolongation, which is slightly more than that identified in adults. Obesity may be one of the most common causes of prolonged QTc Interval duration (El Gamal et al., 1995). In this study of overweight-obese adolescents, $34 \%$ of total participants were considered to have prolonged QTc Interval duration. These findings may simply suggest that obesity throughout both impaired and normal glucose tolerance groups played a more essential role in QTc Interval duration than glucose tolerance alone.

Literature suggests that diastolic dysfunction may be an early complication of IGT (Fujita et al., 2007), and LVH has been shown to increase with increasing glucose intolerance. No significant difference was noted between overweight-obese adolescents with or without IGT for Cornell voltage measures for LVH. Although IGT was identified in study participants within this sample, its degree and duration is unknown, and this could have influenced study findings. In addition, none of the 128 participants in this study were considered to have LVH, according to the criterion utilized.

\section{Aim Three}

Aim three examined differences between blood pressure groups (elevated blood pressure vs. non-hypertension) for dependent variables of HRV, QTc duration, and Cornell voltage measures for LVH in overweight-obese adolescents. The results revealed no significant difference between blood pressure groups for HRV measures (SDNN and $\mathrm{HF}$ ) and QTc Interval duration, but the elevated blood pressure group did exhibit higher Cornell voltage measures for LVH than the non-hypertension group $(p=0.004)$.

Within this sample, $51 \%$ of the overweight-obese adolescents were hypertensive, far exceeding research reporting that $30 \%$ of overweight children have elevated blood pressure (McCarthy, Yancey, Siegel, Wong, Ward, Leslie, et al., 2008). In this sample of overweight-obese adolescents, HRV measures of SDNN and HF were relatively similar for both elevated blood pressure and non-hypertension groups. As previously addressed literature reports when hypertension is present, SDNN measures of HRV are reduced (Alter et al., 2006). No significant difference was identified for HRV measures of SDNN or HF between the blood pressure groups. Kocak and colleagues (1999) suggest children with hypertension have been identified to have an increased risk of developing QTc prolongation. Within this study, no significant differences were noted between adolescent blood pressure groups for QTc Interval duration. It should be noted however that Franchi and colleagues (1996) reported that no differences were identified in HRV measures or QTc Interval duration when mild hypertension was present. The elevated 
blood pressure group consisted of both the pre-hypertension and hypertension subjects and the mean systolic and diastolic measures of blood pressure were not severe. Subjects were also classified based on single rather than multiple blood pressure readings. Age and gender variations have also been reported for HRV measures that might have influenced study findings. Results of our study suggest that in youth elevations in blood pressure do not further contribute to lower HRV measures or more prolonged QTc duration when overweight-obesity is present.

Overweight-obese youth with elevated blood pressure had higher mean Cornell voltage measures for $\mathrm{LVH}$ than non-hypertensive peers $(0.95 \mathrm{mV}$ vs. $0.76 \mathrm{mV})$, respectively. This supports findings that in obese (Wilborn, Beckham, Campbell, Harvey, Galbreath, La Bounty, et al., 2005) and non-obese (Liebson, 2002) subjects, an association exists between elevation in blood pressure and LVH. Although no subjects in this sample were considered to have LVH, there is a trend that should be examined to identify adolescents at risk.

\begin{abstract}
Aim Four
Aim four examined differences between black and white overweight-obese adolescents for dependent variables of HRV, QTc duration, and Cornell voltage measures for LVH. The results revealed no significant difference between black and white overweight-obese adolescents for HRV measure of high frequency (HF), QTc duration, or Cornell voltage measures for LVH, but a statistically significant difference $(p=0.000)$ did exist for circadian fluctuation measures of SDNN between race groups.

SDNN is one of the most predictive values of HRV for mortality (Lampert et al., 2005). The statistically lower measures of SDNN in blacks supports findings noted in adults that minorities are more likely to have decreased SDNN than whites, and it has been postulated to result from possible genetic differences or daily societal stress in the minority population vs. whites (Lampert et al., 2005). However, our findings were contrary to study findings that suggest no significant difference exists in SDNN between healthy non-obese African American and white adolescents (Wang, Thayer, Treiber, \& Sneider, 2005), but obesity in this sample indicates a key difference from healthy subjects. Altered autonomic function has been found already to be present in subjects with a family history of hypertension (Wu, Lu, Yang, Lin, Chen, Wu, et al., 2008). In our study, as noted above, $51 \%$ of participants were also hypertensive, and $60 \%$ of these hypertensive subjects were black. Family history of hypertension was not examined, which could have contributed to lower circadian fluctuations in blacks vs. whites.

There was no significant difference noted between black and whites for HF measures of HRV in this study. In adults it has been reported that blacks have higher HF measures than whites (Liao et al., 1995). Contrary findings in youth for HRV measures identified lower HF measures in African American vs. whites in healthy adolescents (Faulkner et al., 2003).
\end{abstract}


Divergent results have been reported in regards to race for QT Interval prolongation in blacks and whites. Though studies were not identified that examined this factor in adolescents, in adults conflicting reports state that in blacks vs. whites QT Interval duration is shorter (Dekker, et al., 2004), prolonged (Sgarbossa et al., 2000), and not even affected by race (Peeters et al., 2008). In this study of black and white overweight-obese youth, no significant difference was identified for QT Interval duration between race groups. The overall marked obesity throughout the sample could have contributed to this finding, because obesity is one of the most common causes of QT prolongation (El Gamal et al., 1995).

Blacks have an increased incidence of LVH and elevated blood pressure than whites (Coughlin, Gottdiener, Baughman, Wasserman, Marx, Tefft et al., 1994). No significant differences were noted between black and white overweight-obese youth for Cornell voltage measures for LVH. However, no participants were considered to have $\mathrm{LVH}$, regardless of race.

\section{Strengths and Limitations}

Strengths of this study include having a single blinded individual for analysis of QTc duration and electrical voltage measurements for LVH. This increases consistency and strengthens the study results as compared to analysis by multiple individuals. This study utilized a 2-hour post glucose load as well as fasting glucose to determine IGT; this method has been noted to be more effective than fasting glucose alone (Cruz et al., 2005). An adequate sample size obtained from a larger study using secondary analysis of data were a cost effective method, allowing the researcher to examine several variables in overweight-obese adolescents. Because original data were collected within a 250-mile radius of a metropolitan city, findings can be generalized to both urban and rural populations. As noted, studies could not be identified that examined glucose tolerance, hypertension, and race in overweight-obese adolescents in regards to HRV, QTc duration, and electrical voltage criteria for $\mathrm{LVH}$, and these findings will greatly contribute to this identified gap in the literature.

Furthermore, several limitations also exist in association with the study design. Secondary analysis of data is cost effective and beneficial but has drawbacks including the potential for bias. This bias could be related to the fact that original data were not collected to examine these variables within this population. The original data were obtained from a larger study, which investigated potential racial differences associated with IGT in overweight-obese youth, and although quite similar the original goals were not aligned with the goals of this study. Another limitation is the inequality of groups within the study: $71.9 \%$ of the sample had a normal glucose tolerance, $63.3 \%$ were female, and $95.3 \%$ were considered obese, according to age and gender percentiles. The researcher also had to assume that during the original study all data were collected accurately, as specified in the study criteria. In addition, elevated blood pressure was identified in subjects using a single blood pressure reading. 


\section{Theoretical Implications}

The conceptual model for this study identified a relationship among all independent and dependent variables. Impaired glucose tolerance (pre-diabetes) is a precursor for T2DM, which alters autonomic function and contributes to decreases in HRV, prolongation of the QT Interval, and hypertension leading to LVH. This study illustrates that IGT (pre- diabetes) had a small association to these variables, as compared to normal glucose tolerant overweight-obese peers, but not significantly. The relationship between elevation in blood pressure and the association to LVH in the model is supported by study findings. The conceptual model hypothesized IGT may be associated with decreased HRV, QTc prolongation, or LVH even prior to the development of T2DM and findings do not support this theory. Additional factors may have been present that were not identified in the model that could have affected the variables studied. For example, physical fitness levels may influence HRV measures and Buchheit, Platat, Oujaa, \& Simon (2007) studied the effects of physical activity and physical fitness in preadolescents for HRV and determined that even regular moderate intense activities may produce favorable improvements in HRV measures. Exercise induced LVH should also be considered, in which discontinuation of physical activity can reverse the physiological adaptation of the heart enlargement (Escudero, Turfano, Rebolledo, Pellegrini, \& Lobrutto, 2004). The conceptual model associates obesity to all independent and dependent variables, and it has been suggested within our study that glucose tolerance, elevated blood pressure, and race may have no additive effect on HRV, QTc duration, or Cornell voltage measures for LVH when obesity is present.

\section{Clinical Practice Implications}

It is important for healthcare providers to be aware that although no significant differences existed within this study between overweight-obese youth with IGT in comparison to normal glucose tolerance, IGT is a precursor for T2DM, and $21 \%$ of obese adolescents have pre-diabetes (American Diabetes Association, 2009). Currently, the American Diabetes Association is not recommending a screening for IGT in children, because evidence does not support the early intervention would delay the onset of T2DM (American Diabetes Association, 2009). But when adolescents are overweight-obese, IGT may present at a young age and the transition to T2DM is shortened (Jolliffe \& Janssen, 2006). Therefore, in overweight-obese youth it is important to assess BMI and RBMI accurately and follow-up with glucose tolerance testing if obesity is present, because obesity in adolescents is significantly associated with abnormal glucose (Plourde, 2006). Prevention is the most important element, and if in overweight-obese adolescents IGT can be identified prior to its advancement to T2DM, alterations in autonomic function leading to decreased HRV, QTc prolongation, and elevations in blood pressure resulting in LVH may all be prevented.

Although a significant difference for QTc was not identified for glucose tolerance, blood pressure, or racial groups, the prevalence of QTc prolongation in this sample of $34 \%$ exceeds that reported in obese adults of $26 \%$ (Rautaharju, P \& Rautaharju, F., 2007). Prolongation of the QT Interval can be acquired genetically, due to adverse drug 
reactions, and as hypothesized in accordance with obesity. Clinicians have always used precaution when prescribing medications that may adversely affect QT duration, especially to individuals with known QT prolongation. Findings from this study suggest the need to consider overweight-obese adolescents at a high risk for QT prolongation when medications are prescribed that affect QT duration and they should be monitored accordingly. This supports the need for 12-lead electrocardiogram analysis in overweight-obese youth to screen for QT prolongation.

The statistically significant difference noted in overweight-obese youth with elevated blood pressure compared to those that were non-hypertensive for Cornell voltage measures suggests that the pathological sequence that takes place in obese adults may also be present in overweight-obese adolescents. But regardless of the pathological sequence, research has identified that elevations in blood pressure in overweight-obese adolescents predicts the need for early intervention strategies to prevent the development of major health concerns (Torrance, McGuire, Lewanczuk, \& McGavock, 2007). An electrocardiogram is a simple and cost-effective screening tool that healthcare providers could use to measure electrical voltage criteria for LVH in overweight-obese youth. Left ventricular hypertrophy is present in a large percentage of individuals with hypertension and accounts for an increased risk of sudden cardiac death (Liebson, 2002). Obtaining a 12-lead electrocardiogram in overweight and obese adolescents with elevated blood pressure can lead to early identification and proper treatment.

In black overweight-obese adolescents, it is important for the healthcare provider to be aware that decreased SDNN may identify individuals at risk for the development of ventricular arrhythmias (Folino, Russo, Bauce, Mazzotti, \& Daliento, 2004). Decreased SDNN may lead to increased sympathetic modulation of the sinus node (Ozdemir, Alyan, Soylu, Topaloglu, Aras, Metin, et al., 2006), which is associated with increased fatigued and may contribute to threatening arrhythmias (Folino et al., 2004). However HRV analysis remains questionable because optimal limits have not been set for clinical use (Malik, 1996). In our study HRV measures of SDNN and HF would not be considered as even moderately depressed and mean values were similar to those identified in healthy non-obese youth (Faulkner et al., 2003). However it should be noted that differences in literary results may be due to variations in sample sizes, differences in measurement techniques, or the affects of physical activity levels on HRV measures.

\section{Recommendations for Future Research}

There were no studies identified that examined LVH in overweight-obese youth using Cornell voltage criteria. Therefore, it was difficult to establish criteria to indicate that LVH was present, so it was presumed to be more proper to examine the Cornell electrical voltage measurements as a continuous variable for analysis and utilize the adult criterion as a standard for reference. Research validating electrical voltage measures for LVH through echocardiogram or magnetic resonance imaging in overweight-obese youth is warranted to establish set criteria. 
Studies are also warranted to identify if family history of hypertension plays a role in black overweight-obese adolescent's susceptibility to autonomic dysfunction, as identified in the Asian adult population. Within our study black overweight-obese youth were noted to have decreased SDNN HRV measures in comparison to white peers, and it would be important to understand the impact that family history of hypertension may have on altered autonomic function within this group as well.

Age and gender differences have been reported to exist for HRV measures, and a larger sample size for sub-analysis would prove to be beneficial. In addition, the overall marked elevation of BMI and RBMI throughout the entire sample warrants future investigation with a more varied weight group, with possible inclusion of healthy weight subjects. This could decrease clustering of BMI and RBMI values. Also, future studies that measure resting blood pressure on three various days of assessment are warranted. This would allow the researcher to determine blood pressure status based upon the recommended National High Blood Pressure Education Program Working Group on High Blood Pressure in Children and Adolescents standards.

\section{Conclusions}

The positive associations between elevated blood pressure and electrical voltage measurements for LVH in overweight-obese adolescents support findings reported in other populations. In addition, although the direct relationship for decreased SDNN (circadian fluctuation) HRV measures in black overweight-obese adolescents is unknown, study findings are consistent with adult study findings within blacks and whites. These findings also identify notable differences found in the overweight-obese group as compared to studies of SDNN in healthy black and white adolescents. Minimal differences were noted in regards to glucose tolerance, blood pressure, and race for this group of overweight-obese adolescents, and results support findings that obesity alone is an independent risk factor for cardiovascular disease (Wilborn et al., 2005). Further studies examining glucose tolerance, blood pressure, and race in adolescents across a more varied weight group are warranted to determine if these factors have an impact on HRV, QTc duration, or electrical voltage criteria for LVH. 


\section{LIST OF REFERENCES}

Alfakih, K., Walters, K., Jones, T., Ridgway, J., Hall, A. S., \& Sivananthan, M. (2004). New gender-specific partition values for ECG criteria of left ventricular hypertrophy: recalibration against cardiac MRI. Hypertension, 44(2), 175-179.

Alter, P., Grimm, W., Vollrath, A., Czerny, F., \& Maisch, B. (2006). Heart rate variability in patients with cardiac hypertrophy-relation to left ventricular mass and etiology. American Heart Journal, 151(4), 829-836.

American Diabetes Association, (2008). Diabetes Statistics and Prevalence, Retrieved February 11, 2008 from http://www.diabetes.org/diabetes-statistics/prevalence.jsp

American Diabetes Association, (2009). Frequently Asked Questions about Pre-diabetes, Retrieved Jan 27, 2009 from http://www.diabetes.org/pre-diabetes/faq.jsp

American Heart Association, (2007). Atrial and Ventricular Depolarization Changes, Retrieved March 5, 2008, from http://www.americanheart.org/presenter.jhtml?identifie $\mathrm{r}=563$

American Heart Association, (2009). Hypertension, Prehypertension in Young Linked with Heart Enlargement, Retrieved Jan 24, 2009 from http://americanheart.mediaroom.com/index.php?s=43\&item $=107$

Antzelevitch, C. (2005). Role of transmural dispersion of repolarization in the genesis of drug-induced torsades de pointes. Heart Rhythm, 2(2 Supplement), S9-15.

Barker, J., McFann, K., \& Orban, T. (2007). Effect of oral insulin on insulin autoantibody levels in the Diabetes Prevention Trial Type 1 oral insulin study. Diabetologia, 50(8), 1603-1606.

Barone, M. (1996). The Harriet Lane Handbook (14 ${ }^{\text {th }}$ ed.), Cardiology (pp. 127-154). St. Louis, MO: Mosby.

Bekezin, V., Kozlova, V., Kozlova, S., \& Igolkina, V. (2008). Peculiarities of cardiovascular syndrome in children and adolescents with obesity in dependence of level of insulin resistance. Kardiologiia, 48(3), 69-74.

Bilan, A., Witczak, A., Palusinski, R., Ignatowicz, A., \& Hanzlik, J. (2005). Circadian rhythm of the QT Interval dispersion in healthy subjects. Correlation with heart rate variability circadian pattern. Journal of Electrocardiology, 38(1), 36-42. 
Bilchick, K., \& Berger, R. (2006). Heart rate variability. Journal of Cardiovascular Electrophysiology, 17(6), 691-694.

Bloom, S., Edwards, A., \& Hardy, R. (1978). The role of the autonomic nervous system in the control of glucagon, insulin and pancreatic polypeptide release from the pancreas. Journal of Physiology, 280, 9-23.

Bobbioni-Harsch, E., Sztajzel, J., Barthassat, V., Makoundou, V., Gastaldi, G., Sievert, K., Chassot, G., Huber, O., Morel, P., Assimacopoulos-Jeannet, F., \& Golay, A. (2009). Independent evolution of heart autonomic function and insulin sensitivity during weight loss. Obesity (Silver Spring), 17(2), 247-253.

Brown, D., Giles, W., Greenlund, K., \& Croft, J. (2001). Disparities in cholesterol screening: falling short of a national health objective. Preventative Medicine, 33(6), 517-522.

Buchheit, M., Platat, C., Oujaa, M., \& Simon, C. (2007). Habitual physical activity, physical fitness and heart rate variability in preadolescents. International Journal of Sports Medicine, 28(3), 204-210.

Butera, G., Bonnet, D., Kachaner, J., Sidi, D., \& Villain, E. (2003). Heart rate variability in children with hypertrophic cardiomyopathy. Heart, 89(2), 205-206.

Caprio, S., Daniels, S., Drewnowski, A., Kaufman, F., Palinkas, L., Rosenbloom, A., Schwimmer, J. (2008). Influence of race, ethnicity, and culture on childhood obesity: implications for prevention and treatment: a consensus statement of Shaping America's Health and the Obesity Society. Diabetes Care, 31(11), 2211-2221.

Carnethon, M., Golden, S., Folsom, A., Haskell, W., \& Liao, D. (2003). Prospective investigation of autonomic nervous system function and the development of type 2 diabetes: the Atherosclerosis Risk In Communities study, 1987-1998. Circulation, 107(17), 2190-2195.

Carnethon, M., Jacobs, D., Sidney, S., \& Liu, K. (2003). Influence of autonomic nervous system dysfunction on the development of type 2 diabetes: the CARDIA study.

Diabetes Care, 26(11), 3035-3041.

Carnethon, M., Prineas, R., Temprosa, M., Zhang, Z., Uwaifo, G., \& Molitch, M. (2006). The association among autonomic nervous system function, incident diabetes, and intervention arm in the diabetes prevention program. Diabetes Care, 29(4), 914919.

Centers for Disease Control and Prevention, (2008). Retrieved Jan 27, 2009 from http://www.cdc.gov/healthyweight/assessing/bmi/index.html 
Centers for Disease Control and Prevention, (2009). Retrieved February 4, 2009 from http://www.cdc.gov/nccdphp/dnpa/obesity/childhood/prevalence.htm

Cincinnati Children's, Left Ventricular Hypertrophy Found in Children Who Appear Healthy, (2007). Retrieved Jan 20, 2009 from http://www.cincinnatichildrens.org/health/subscribe/ped-insights/05-07/leftventricular-hypertrophy.htm

Clarke, B., Ewing, D., \& Campbell, I. (1979). Diabetic autonomic neuropathy. Diabetologia, 17(4), 195-212.

Corrado, D., Bacharova, L., Antzelvitch, C., \& Kanters, J. (2007). How to prevent sudden death in patients with inherited arrhythmias syndromes or cardiomyopathies. Journal of Electrocardiology, 40(1), 62-65.

Coughlin, S., Gottdiener, J., Baughman, K., Wasserman, A., Marx, E., Tefft, M., Gersh, B. (1994). Black-white differences in mortality in idiopathic dilated cardiomyopathy: the Washington, DC, dilated cardiomyopathy study. Journal of the National Medical Association, 86(8), 583-591.

Cruz, M., Shaibi, G., Weigensberg, M., Spruijt-Metz, D., Ball, G., \& Goran, M. (2005). Pediatric obesity and insulin resistance: chronic disease risk and implications for treatment and prevention beyond body weight modification. Annual Review of Nutrition, 25, 435-468.

Dalla Man, C., Campioni, M., Polonsky, K., Basu, R., Rizza, R., Toffolo, G., Cobelli, C. (2005). Two-hour seven-sample oral glucose tolerance test and meal protocol: minimal model assessment of beta-cell responsivity and insulin sensitivity in nondiabetic individuals. Diabetes, 54(11), 3265-3273.

Dehghan, M., Akhtar-Danesh, N., \& Merchant, A. (2005). Childhood obesity, prevalence and prevention. Nutrition Journal, 4, 24.

Dekker, J., Crow, R., Hannan, P., Schouten, E., \& Folsom, A. (2004). Heart ratecorrected QT Interval prolongation predicts risk of coronary heart disease in black and white middle-aged men and women: the ARIC study. Journal of the American College of Cardiology, 43(4), 565-571.

Department of Health and Human Services, Establishing the Precursors of the Metabolic Syndrome in Children, (2003). Retrieved Jan 27, 2009 from http://grants.nih.gov/grants/guide/rfa-files/RFA-HD-03-033.html

Desai, M., Li, L., Desta, Z., Malik, M., \& Flockhart, D. (2003). Variability of heart rate correction methods for the QT Interval. British Journal of Clinical Pharmacology, 55(6), 511-517. 
DiPietro, L., Mossberg, H., \& Stunkard, A. (1994). A 40-year history of overweight children in Stockholm: life-time overweight, morbidity, and mortality. International Journal of Obesity Related Metabolic Disorders, 18(9), 585-590.

Drazner, M. (2004). Left ventricular hypertrophy is more common in black than white hypertensives, is this news? Hypertension, 43, 1160.

Ebinc, H., Ebinc, F., Ozkurt, Z., Dogru, T., \& Yilmaz, M. (2006). Relationship of left ventricular mass to insulin sensitivity and body mass index in healthy individuals. Acta Cardiologica, 61(4), 398-405.

Eckel, R. (2003). Obesity Mechanisms and Clinical Management. (pp. 183-191). Philadelphia, PA: Lippincott, Williams, \&Wilkins.

Edhouse, J., Thakur, R., \& Khalil, J. (2002). ABC of clinical electrocardiography. Conditions affecting the left side of the heart. British Medical Journal, 324(7348), 1264-1267.

El-Gamal, A., Gallagher, D., Nawras, A., Gandhi, P., Gomez, J., Allison, D., Steinberg, J., Shumacher, D., Blank, R. \& Heymsfield, S. (1995). Effects of obesity on QT, RR, and QTc Intervals. The American Journal of Cardiology, 75, 956-959.

Escudero, E., Tufare, A., Rebolledo, O., Pellegrini, L., \& Lobrutto, C. (2004). Serum carboxyl-terminal propeptide of procollagen type I in exercise-induced left ventricular hypertrophy. Clinical Cardiology, 27(8), 471-474.

Family Blood Pressure Program. Left ventricular hypertrophy, (2008). Retrieved March 23, 2008, from http://www.sph.uth.tmc.edu/hgc/fbpp/techSigLVH.htm

Faulkner, M., Hathaway, D., \& Tolley, B. (2003). Cardiovascular autonomic function in healthy adolescents. Heart Lung, 32(1), 10-22.

Faulkner, M., Quinn, L., Rimmer, J., \& Rich, B. (2005). Cardiovascular endurance and heart rate variability in adolescents with type 1 or type 2 diabetes. Biological Research for Nursing, 7(1), 16-29.

Felber Dietrich, D., Ackermann-Liebrich, U., Schindler, C., Barthelemy, J. C., Brandli, O., Gold, D., Gold, D., Knopfli, B., Probst-Hensch, N., Roche, F., Tschopp, J., von Eckardstein, A., \& Gaspoz, J. (2008). Effect of physical activity on heart rate variability in normal weight, overweight and obese subjects: results from the SAPALDIA study. European Journal of Applied Physiology, 104(3), 557-565.

Flower, K., Perrin, E., Viadro, C., \& Ammerman, A. (2007). Using body mass index to identify overweight children: barriers and facilitators in primary care. Journal of the Ambulatory Pediatric Association, 7(1), 38-44. 
Flynn, J., \& Alderman, M. (2005). Characteristics of children with primary hypertension seen at a referral center. Pediatric Nephrology, 20(7), 961-966.

Folino, A., Russo, G., Bauce, B., Mazzotti, E., \& Daliento, L. (2004). Autonomic profile and arrhythmic risk stratification after surgical repair of tetralogy of Fallot. American Heart Journal, 148(6), 985-989.

Foppa, M., Duncan, B., Arnett, D., Benjamin, E., Liebson, P., Manolio, T., Skelton, T. (2006). Diabetes, gender, and left ventricular structure in African-Americans: the atherosclerosis risk in communities study. Cardiovascular Ultrasound, 4, 43.

Franchi, F., Lazzeri, C., \& LaVilla, G. (1996). Twenty-four hour analysis of QT Interval and heart rate variability in patients with essential hypertension. American Journal of Hypertension, 9(4) (Supplement 1), 48a.

Fujita, M., Asanuma, H., Kim, J., Liao, Y., Hirata, A., Tsukamoto, O., Minamino, T., Hori, M., Goto, M., Node, K., \& Kitakaze, M. (2007). Impaired glucose tolerance: a possible contributor to left ventricular hypertrophy and diastolic dysfunction. International Journal of Cardiology, 118(1), 76-80.

Fukushige, T., Yoshinaga, M., Shimago, A., Nishi, J., Kono, Y., Nomura, Y., Miyata, K., Imamura, M., Shibata, T., Nagashima, M., \& Niimura, I. (2002). Effect of age and overweight on the QT Interval and the prevalence of long QT syndrome in children. American Journal of Cardiology, 89(4), 395-398.

Furukawa, Y., Shimizu, H., Hiromoto, K., Kanemori, T., Masuyama, T., \& Ohyanagi, M. (2006). Circadian variation of beat-to-beat QT Interval variability in patients with prior myocardial infarction and the effect of beta-blocker therapy. Pacing Clinical Electrophysiology, 29(5), 479-486.

Galeev, A., Igisheva, L., \& Kazin, E. (2002). Heart rate variability in healthy six- to sixteen year old children. Fiziologiia Cheloveka, 28(4), 54-58.

Gang, Y., \& Malik, M. (2003). Heart rate variability analysis in general medicine. Indian Pacing Electrophysiology Journal, 3(1), 34-40.

Gertsch, M. (2004). The ECG: A Two-Step Approach to Diagnosis. (pp. 55-58). Verlag Berlin, Heidelberg: Springer.

Girola, A., Enrini, R., Garbetta, F., Tufano, A., \& Caviezel, F. (2001). QT dispersion in uncomplicated human obesity. Obesity Research, 9(2), 71-77.

Goodacre, S., \& McLeod, K. (2002). ABC of clinical electrocardiography: Paediatric electrocardiography. British Medical Journal, 324(7350), 1382-1385. 
Goran, M., Ball, G., \& Cruz, M. (2003). Obesity and risk of type 2 diabetes and cardiovascular disease in children and adolescents. Journal of Clinical Endocrinology and Metabolism, 88(4), 1417-1427.

Greenbaum, C., Mandrup-Poulsen, T., McGee, P., Battelino, T., Haastert, B., Ludvigsson, J., Pozzilli, P., Lachin, J., \& Kolb, H. (2008). Mixed-meal tolerance test versus glucagon stimulation test for the assessment of beta-cell function in therapeutic trials in type 1 diabetes. Diabetes Care, 31(10), 1966-1971.

Greene, D., Feldman, E., Stevens, M., Sima, A., Albers, J., \& Pfeifer, M. (1997). Diabetic neuropathy. In D. J. Porte \& R. S. Sherwin (Eds.), Ellenberg and Rifkins's Diabetes Mellitus: Theory and Practice ( $5^{\text {th }}$ ed.), (pp. 1423). Stamford, Connecticut: Appleton \& Lange.

Guizar, J., Ahuatzin, R., Amador, N., Sanchez, G., \& Romer, G. (2005). Heart autonomic function in overweight adolescents. Indian Pediatrics, 42(5), 464-469.

Guo, S., Wu, W., Chumlea, W., \& Roche, A. (2002). Predicting overweight and obesity in adulthood from body mass index values in childhood and adolescence. American Journal of Clinical Nutrition, 76(3), 653-658.

Gutin, B., Barbeau, P., Litaker, M., Ferguson, M., \& Owens, S. (2000). Heart rate variability in obese children: relations to total body and visceral adiposity, and changes with physical training and detraining. Obesity Research, 8(1), 12-19.

Gutin, B., Howe, C., Johnson, M., Humphries, M., Snieder, H., \& Barbeau, P. (2005). Heart rate variability in adolescents: relations to physical activity, fitness, and adiposity. Medicine and Science in Sports Exercise, 37(11), 1856-1863.

Gutin, B., Owens, S., Slavens, G., Riggs, S., \& Treiber, F. (1997). Effect of physical training on heart-period variability in obese children. Journal of Pediatrics, 130(6), 938-943.

Haapalahti, P., Viitasalo, M., Perhonen, M., Makijarvi, M., Vaananen, H., Oikarinen, L., Hekkala, A., Salorinne, Y., Swan, H., \& Toivonen, L. (2006). Ventricularrepolarization and heart rate responses during cardiovascular autonomic function testing in LQT1 subtype of long QT syndrome. Pacing Clinical Electrophysiology, 29(10), 1122-1129.

Healthy People 2010, Leading Health Indicators Priorities for Action, (2004). Retrieved Jan 24, 2009 from http://www.healthypeople.gov/LHI/Priorities.htm 
Henry, R., Kamp, O., Kostense, P., Spijkerman, A., Dekker, J., van Eijck, R., Nijpels, G., Heine, R., Bouter, L., \& Stehouwer, C. (2004). Left ventricular mass increases with deteriorating glucose tolerance, especially in women: independence of increased arterial stiffness or decreased flow-mediated dilation: the Hoorn study. Diabetes Care, 27(2), 522-529.

Hoskings, D., Bennett, T., \& Hampton, J. (1978). Diabetic autonomic neuropathy. Diabetes, 27, 1043-1054.

Hunt, A. (2005). Accuracy of popular automatic QT Interval algorithms assessed by a 'gold standard' and comparison with a Novel method: computer simulation study. BMC Cardiovascular Disorders, 5, 29.

Ippisch, H., \& Daniels, S. (2008). Hypertension in overweight and obese children. Progress in Pediatric Cardiology, 25 (2), 177-182.

Ishida, S., Nakagawa, M., Fujino, T., Yonemochi, H., Saikawa, T., \& Ito, M. (1997). Circadian variation of QT Interval dispersion: correlation with heart rate variability. Journal of Electrocardiology, 30(3), 205-210.

Jolliffe, C. J., \& Janssen, I. (2006). Vascular risks and management of obesity in children and adolescents. Vascular Health and Risk Management, 2(2), 171-187.

Kahan, T., \& Bergfeldt, L. (2005). Left ventricular hypertrophy in hypertension: its arrhythmogenic potential. Heart, 91(2), 250-256.

Karason, K., Molgaard, H., Wikstrand, J., \& Sjostrom, L. (1999). Heart rate variability in obesity and the effect of weight loss. American Journal of Cardiology, 83(8), 12421247.

Karavanaki-Karanassiou, K. (2001). Autonomic neuropathy in children and adolescents with diabetes mellitus. Journal of Pediatric Endocrinology and Metabolism, 14 Supplement 5, 1379-1386.

Kaufman, C., Kaiser, D., Steinberger, J., Kelly, A., \& Dengel, D. (2007). Relationships of cardiac autonomic function with metabolic abnormalities in childhood obesity. Obesity (Silver Spring), 15(5), 1164-1171.

Khan, F., Kerr, H., Ross, R., Newton, D., \& Belch, J. (2006). Effects of poor glucose handling on arterial stiffness and left ventricular mass in normal children. International Angiology, 25(3), 268-273.

Khositseth, A., Suthutvoravut, U., Chongviriyaphan, N., \& Ruangkanchanasetr, S. (2006). Cardiac dimensions and function in children with obesity. Indian Heart Journal, 58(6), 422-425. 
Kocak, G., Atalay, S., Bakkaloglu, S., Ekim, M., Tutar, H. E., \& Imamoglu, A. (1999). QT/corrected QT (QTc) Intervals and QT/QTc dispersions in children with chronic renal failure. International Journal of Cardiology, 70(1), 63-67.

Kulan, K., Ural, D., Komsuoglu, B., Agacdiken, A., Goldeli, O., \& Komsuoglu, S. S. (1998). Significance of QTc prolongation on ventricular arrhythmias in patients with left ventricular hypertrophy secondary to essential hypertension. International Journal of Cardiology, 64(2), 179-184.

Lampert, R., Ickovics, J., Horwitz, R., \& Lee, F. (2005). Depressed autonomic nervous system function in African Americans and individuals of lower social class: a potential mechanism of race- and class-related disparities in health outcomes. American Heart Journal, 150(1), 153-160.

Lanjewar, P., Pathak, V., \& Lokhandwala, Y. (2004). Issues in QT Interval measurement. Indian Pacing Electrophysiology Journal, 4(4), 156-161.

Legro, R., Kunselman, A., Dodson, W., \& Dunaif, A. (1999). Prevalence and predictors of risk for type 2 diabetes mellitus and impaired glucose tolerance in polycystic ovary syndrome: a prospective, controlled study in 254 affected women. Journal of Clinical Endocrinology and Metabolism, 84(1), 165-169.

Liao, D., Barnes, R., Chambless, L., Simpson, R., Sorlie, P., \& Heiss, G. (1995). Age, race, and sex differences in autonomic cardiac function measured by spectral analysis of heart rate variability--the ARIC study. Atherosclerosis Risk in Communities. American Journal of Cardiology, 76(12), 906-912.

Liebson, P. (2002). Epidemiologic and pathophysiologic considerations in the design of clinical trials to evaluate its regression. Heart Drug, 2, 142-156.

Lundblad, D., \& Eliasson, M. (2003). Silent myocardial infarction in women with impaired glucose tolerance: the Northern Sweden MONICA study. Cardiovascular Diabetology, 2, 9.

Lustig, R. (2001). The neuroendocrinology of childhood obesity. Pediatric Clinics of North America, 48(4), 909-930.

Lustig, R. (2003). Autonomic dysfunction of the beta-cell and the pathogenesis of obesity. Reviews in Endocrine and Metabolic Disorders, 4(1), 23-32.

Malik, M. (1996). Heart rate variability standards of measurement, physiological interpretation, and clinical use. Circulation, 93, 1043-1065.

Malik, M., Farbom, P., Batchvarov, V., Hnatkova, K., \& Camm, A. (2002). Relation between QT and RR Intervals is highly individual among healthy subjects: implications for heart rate correction of the QT Interval. Heart, 87(3), 220-228. 
Marena, S., Montegrosso, G., De Michieli, F., Pisu, E., \& Pagano, G. (1992).

Comparison of the metabolic effects of mixed meal and standard oral glucose tolerance test on glucose, insulin and C-peptide response in healthy, impaired glucose tolerance, mild and severe non-insulin-dependent diabetic subjects. Acta Diabetologica, 29(1), 29-33.

Martini, G., Riva, P., Rabbia, F., Molini, V., Ferrero, G., Cerutti, F., Carra, R., \& Veglio, F. (2001). Heart rate variability in childhood obesity. Clinical Autonomic Research, $11(2), 87-91$.

Massin, M., \& von Bernuth, G. (1997). Normal ranges of heart rate variability during infancy and childhood. Pediatric Cardiology, 18(4), 297-302.

McCance, K., \& Huether, S. (2002). Pathophysiology The Biologic Basis for Disease in Adults and Children ( $4^{\text {th }}$ ed.), (pp. 363-541). St. Louis, MO: Mosby.

McCarthy, W., Yancey, A., Siegel, J., Wong, W., Ward, A., Leslie, J., Gonzales, E. (2008). Correlation of obesity with elevated blood pressure among racial/ethnic minority children in two Los Angeles middle schools. Preventing Chronic Disease, 5(2), A46.

McLaughlin, T., Allison, G., Abbasi, F., Lamendola, C., \& Reaven, G. (2004). Prevalence of insulin resistance and associated cardiovascular disease risk factors among normal weight, overweight, and obese individuals. Metabolism, 53(4), 495499.

McNiece, K., Poffenbarger, T., Turner, J., Franco, K., Sorof, J., \& Portman, R. (2007). Prevalence of hypertension and pre-hypertension among adolescents. Journal of Pediatrics, 150(6), 640-644.

McMillan, D. (2002). Interpreting heart rate variability sleep/wake patterns in cardiac patients. Journal of Cardiovascular Nursing, 17(1), 69-81.

Moss, A., \& Allen, H. (2001). Moss and Adams' Heart Disease in Infants Children, and Adolescents Including the Fetus and the Young Adult. (6 $6^{\text {th }}$ ed.), (pp. 58-342). Philadelphia, PA: Lippincott, Williams, \& Wilkins.

Must, A., Jacques, P., Dallal, G., Bajema, C., \& Dietz, W. (1992). Long-term morbidity and mortality of overweight adolescents. A follow-up of the Harvard Growth Study of 1922 to 1935. New England Journal of Medicine, 327(19), 1350-1355.

Nagai, N., Matsumoto, T., Kita, H., \& Moritani, T. (2003). Autonomic nervous system activity and the state and development of obesity in Japanese school children. Obesity Research, 11(1), 25-32. 
Nagai, N., \& Moritani, T. (2004). Effect of physical activity on autonomic nervous system function in lean and obese children. International Journal of Obesity Related Metabolic Disorders, 28(1), 27-33.

Nault, I., Nadreau, E., Paquet, C., Brassard, P., Marceau, P., Marceau, S., Biron, S., Hould, F., Lebel, S., Richard, D., \& Poirier, P. (2007). Impact of bariatric surgery-induced weight loss on heart rate variability. Metabolism, 56(10), 1425-1430.

Nieto, F., Szklo, M., \& Comstock, G. (1992). Childhood weight and growth rate as predictors of adult mortality. American Journal of Epidemiology, 136(2), 201-213.

Obesity Society, Childhood Overweight, (2009). Retrieved February 7, 2009 from http://www.obesity.org/information/childhood_overweight.asp

O'Brien, M., Nader, P., Houts, R., Bradley, R., Friedman, S., Belsky, J., Susman, E. (2007). The ecology of childhood overweight: a 12-year longitudinal analysis. International Journal of Obesity (London), 31(9), 1469-1478.

Olivares Lopez, J., Vazquez Olivares, M., Fleta Zaragozano, J., Moreno Aznar, L., \& Bueno Sanchez, M. (2005). Electrocardiographic and echocardiographic findings in children with overweight and obesity. Medicina Clinica, 125(3), 93-94.

Ozdemir, O., Alyan, O., Soylu, M., Topaloglu, S., Aras, D., Metin, F., Geyik, B., Ozbakir, C., \& Demir, A. (2006). Relation between sympathetic overactivity and left atrial spontaneous echo contrast in patients with mitral stenosis and sinus rhythm. Heart, Lung, and Circulation, 15(4), 242-247.

Pal, G., Pal, P., Nanda, N., Amudharaj, D., \& Karthik, S. (2009). Spectral analysis of heart rate variability (HRV) may predict the future development of essential hypertension. Medical Hypotheses, 72(2), 183-185.

Pappachan, J., Sebastian, J., Bino, B., Jayaprakash, K., Vijayakumar, K., Sujathan, P., Adinegara, L. (2008). Cardiac autonomic neuropathy in diabetes mellitus: prevalence, risk factors and utility of corrected QT Interval in the ECG for its diagnosis. Postgraduate Medical Journal, 84(990), 205-210.

Pearl, W. (1996). Effects of gender, age, and heart rate on QT Intervals in children. Pediatric Cardiology, 17(3), 135-136.

Peeters, M., Janssen, K., Kakuda, T., Scholler-Gyure, M., Lachaert, R., Hoetelmans, R. M., Woodfall, B., \& DeSmedt, G. (2008). Etravirine has no effect on QT and corrected QT Interval in HIV-negative volunteers. Annals Pharmacotherapy, 42(6), 757-765. 
Perciaccante, A., Fiorentini, A., Paris, A., Serra, P., \& Tubani, L. (2006). Circadian rhythm of the autonomic nervous system in insulin resistant subjects with normoglycemia, impaired fasting glycemia, impaired glucose tolerance, type 2 diabetes mellitus. BMC Cardiovascular Disorders, 6, 19.

Pewsner, D., Juni, P., Egger, M., Battaglia, M., Sundstrom, J., \& Bachmann, L. (2007). Accuracy of electrocardiography in diagnosis of left ventricular hypertrophy in arterial hypertension: systematic review. British Medical Journal, 335(7622), 711.

Pletcher, M., Bibbins-Domingo, K., Lewis, C., Wei, G., Sidney, S., Carr, J., Vittinghoff, E., McCulloch, C., \& Hulley, S. (2008). Prehypertension during young adulthood and coronary calcium later in life. Annals of Internal Medicine, 149(2), 91-99.

Plourde, G. (2006). Preventing and managing pediatric obesity. Recommendations for family physicians. Canadian Family Physician, 52, 322-328.

Poirier, P., Giles, T., Bray, G., Hong, Y., Stern, J., Pi-Sunyer, F., Eckel, R. (2006). Obesity and cardiovascular disease: pathophysiology, evaluation, and effect of weight loss. Arteriosclerosis, Thrombosis, and Vascular Biology, 26(5), 968-976.

Prasad, S., Furr, A., Zhang, S., Ball, S., \& Allen, A. (2007). Baseline values from the electrocardiograms of children and adolescents with ADHD. Child and Adolescent Psychiatry and Mental Health, 1(1), 11.

Qureshi, A., Suri, M., Kirmani, J., Divani, A., \& Mohammad, Y. (2005). Is prehypertension a risk factor for cardiovascular diseases? Stroke, 36(9), 1859-1863.

QT Syndrome, (2005). Retrieved March 23, 2008, from, http://www.qtsyndrome.ch/faq.html

Rabbia, F., Silke, B., Conterno, A., Grosso, T., De Vito, B., Rabbone, I., Chiandussi, L. \& Veglio, F., (2003). Assessment of cardiac autonomic modulation during adolescent obesity. Obesity Research, 11(4), 541-548.

Rana, B., Lim, P., Naas, A., Ogston, S., Newton, R., Jung, R., Morris, A., Struthers, A. (2005). QT Interval abnormalities are often present at diagnosis in diabetes and are better predictors of cardiac death than ankle brachial pressure index and autonomic function tests. Heart, 91(1), 44-50.

Rautaharju, P. \& Rautaharju, F. (2007). Investigative Electrocardiology in Epidemiological Studies and Clinical Trials, (pp. 202-230). Verlag, London: Springer.

Reed, M., Robertson, C., \& Addison, P. (2005). Heart rate variability measurements and the prediction of ventricular arrhythmias. QJM: An International Journal of Medicine, 98(2), 87-95. 
Rijnbeek, P., van Herpen, G., Kapusta, L., Ten Harkel, A., Witsenburg, M., \& Kors, J. (2008). Electrocardiographic criteria for left ventricular hypertrophy in children. Pediatric Cardiology, 5, 923-928.

Rodbard, H. (2008). Diabetes screening, diagnosis, and therapy in pediatric patients with type 2 diabetes. Medscape Journal of Medicine, 10(8), 184; quiz 184.

Rubenstein, A. (2005). Obesity: a modern epidemic. Transactions of the American Clinical and Climatology Association, 116, 103-111; discussion 112-103.

Ryan, M. (2005). Obesity spells danger from an early age. Diabetes Management, 13(1), $25-26$.

Schroeder, E., Chambless, L., Liao, D., Prineas, R., Evans, G., Rosamond, W., Heiss, G. (2005). Diabetes, glucose, insulin, and heart rate variability: the Atherosclerosis Risk in Communities (ARIC) study. Diabetes Care, 28(3), 668-674.

Scott, L., \& Kench, P. (2004). Cardiac autonomic neuropathy in the diabetic patient: does 123I-MIBG imaging have a role to play in early diagnosis? Journal of Nuclear Medicine Technology, 32(2), 66-71.

Science Blog, Obesity May Exacerbate a Heart Disorder in African American Females, (2002). Retrieved Jan 25, 2009 from http://www.scienceblog.com/community/older/2002/A/2002860.html

Sekine, M., Izumi, I., Yamagami, T., \& Kagamimori, S. (2001). Obesity and cardiac autonomic nerve activity in healthy children: results of the toyama birth cohort study. Environmental Health and Preventative Medicine, 6 (3), 149-153.

Semizel, E., Ozturk, B., Bostan, O., Cil, E., \& Ediz, B. (2008). The effect of age and gender on the electrocardiogram in children. Cardiology in the Young, 18, 26-40.

Sgarbossa, E., Pinski, S., Williams, D., Pavlovic-Surjancev, B., Tang, J., \& Trohman, R. (2000). Comparison of QT Intervals in African-Americans versus Caucasians. American Journal of Cardiology, 86(8), 880-882.

Silvetti, M., Drago, F., \& Ragonese, P. (2001). Heart rate variability in healthy children and adolescents is partially related to age and gender. International Journal of Cardiology, 81(2-3), 169-174.

Singh, J., Larson, M., O'Donnell, C., Wilson, P., Tsuji, H., Lloyd-Jones, D., Levy, D. (2000). Association of hyperglycemia with reduced heart rate variability (The Framingham Heart Study). American Journal of Cardiology, 86(3), 309-312.

Simmons, D. (1994). Pathogenesis of diabetic neuropathy. In C. R. Kahn \& G. C. Weir (Eds.), Joslin's Diabetic Neuropathy (13 ${ }^{\text {th }}$ ed.), (pp. 665-690). Philadelphia, PA: Lee \& Febiger. 
Singhal, V., Schwenk, W., \& Kumar, S. (2007). Evaluation and management of childhood and adolescent obesity. Mayo Clinic Proceedings, 82(10), 1258-1264.

Soares, P., Moreno, A., Cravo, S., \& Nobrega, A. (2005). Coronary artery bypass surgery and longitudinal evaluation of the autonomic cardiovascular function. Critical Care, 9(2), R124-131.

Solders, G., Persson, A., \& Wilczek, H. (1986). Autonomic system dysfunction and polyneuropathy in nondiabetic uremia. A one-year follow-up study after renal transplantation. Transplantation, 41(5), 616-619.

Sorof, J., \& Daniels, S. (2002). Obesity hypertension in children: a problem of epidemic proportions. Hypertension, 40(4), 441-447.

Surawicz, B., \& Parikh, S. (2003). Differences between ventricular repolarization in men and women: description, mechanism and implications. Annals of Noninvasive Electrocardiology, 8(4), 333-340.

Suys, B., Heuten, S., De Wolf, D., Verherstraeten, M., de Beeck, L., Matthys, D., Vrints, C. Rooman, R. (2006). Glycemia and corrected QT Interval prolongation in young type 1 diabetic patients: what is the relation? Diabetes Care, 29(2), 427-429.

Takebayashi, K., Aso, Y., Matsutomo, R., Wakabayashi, S., \& Inukai, T. (2004). Association between the corrected QT Intervals and combined intimal-medial thickness of the carotid artery in patients with type 2 diabetes. Metabolism, 53(9), 1152-1157.

Tentolouris, N., Liatis, S., \& Katsilambros, N. (2006). Sympathetic system activity in obesity and metabolic syndrome. Annals of the New York Academy of Sciences, 1083, 129-152.

Texas Heart Institute, Long Q-T Syndrome, (2007). Retrieved March 24, 2008, from http://www.texasheartinstitute.org/HIC/Topics/Cond/longqts.cfm

Toivonen, L. (2002). More light on QT Interval measurement. Heart, 87(3), 193-194.

Torrance, B., McGuire, K., Lewanczuk, R., \& McGavock, J. (2007). Overweight, physical activity and high blood pressure in children: a review of the literature. Vascular Health and Risk Management, 3(1), 139-149.

United States Department of Health and Human Services, Childhood Obesity, (2009) Retreived March 8, 2009 from http://aspe.hhs.gov/health/reports/child_obesity/ 
Urbina, E., Bao, W., Pickoff, A., \& Berenson, G. (2002). Race (black-white) differences in heart rate variability measures during cardiovascular stress testing in healthy male adolescents: the bogulusa heart study. American Journal of Hypertension, 9, (4) Supplement 1.24a.

Valensi, P., Paries, J., \& Attali, J. (2003). Cardiac autonomic neuropathy in diabetic patients: influence of diabetes duration, obesity, and microangiopathic complications-the French multicenter study. Metabolism, 52(7), 815-820.

Varechova, S., Durdik, P., Cervenkova, V., Ciljakova, M., Banovcin, P., \& Hanacek, J. (2007). The influence of autonomic neuropathy on cough reflex sensitivity in children with diabetes mellitus type 1. Journal of Physiological Pharmacology, 58 Supplement 5(Pt 2), 705-715.

Vasan, R. (2003). Cardiac function and obesity. Heart, 89(10), 1127-1129.

Velasquez-Mieyer, P., Neira, C., Nieto, R., \& Cowan, P. (2007). Obesity and cardiometabolic syndrome in children. Therapeutic Advances in Cardiovascular Disease, 1(1), 61-81.

Velasquez-Mieyer, P., Perez-Faustinelli, S., \& Cowan, P. (2005). Identifying children at risk for obesity, type 2 diabetes, and cardiovascular disease. Diabetes Spectrum, 18, 213-220.

Viitasalo, M., Karjalainen, J., Makijarvi, M., \& Toivonen, L. (1998). Autonomic modulation of QT Intervals in post-myocardial infarction patients with and without ventricular fibrillation. American Journal of Cardiology, 82(2), 154-159.

Vinod Porwal, P. (2005). QT Interval in Diabetes Mellitus. International Journal of Diabetes in Developing Countries, 25(2), 46-49.

Wang, Y., Ge, K., \& Popkin, B. (2000). Tracking of body mass index from childhood to adolescence: a 6-y follow-up study in China. American Journal of Clinical Nutrition, 72(4), 1018-1024.

Wang, X., Thayer, J., Treiber, F., \& Snieder, H. (2005). Ethnic differences and heritability of heart rate variability in African- and European American youth. American Journal of Cardiology, 96(8), 1166-1172.

Wawryk, A., Bates, D., \& Couper, J. (1997). Power spectral analysis of heart rate variability in children and adolescents with IDDM. Diabetes Care, 20(9), 1416-1421.

Webster, M., \& Scott, R., (1997). What cardiologists need to know about diabetes. Lancet, 350 Supplement 1, SI23-28. 
Wilborn, C., Beckham, J., Campbell, B., Harvey, T., Galbreath, M., La Bounty, P., Nassar, E., Wismann, J., \& Kreider, R. (2005). Obesity: prevalence, theories, medical consequences, management, and research directions. Journal of International Society of Sports Nutrition, 2, 4-31.

Wong, K., Lim, P., Wong, S., MacWalter, R., Struthers, A., \& MacDonald, T. (2003). Does a prolonged QT peak identify left ventricular hypertrophy in hypertension? International Journal of Cardiology, 89(2-3), 179-186.

Wu, J., Lu, F., Yang, Y., Lin, T., Chen, J., Wu, C., Haung, Y., Chang, C. (2008). Epidemiological study on the effect of pre-hypertension and family history of hypertension on cardiac autonomic function. Journal of the American College of Cardiology, 51(19), 1896-1901.

Wylie, G., Hungin, A., \& Neely, J. (2002). Impaired glucose tolerance: qualitative and quantitative study of general practitioners' knowledge and perceptions. British Medical Journal, 324(7347), 1190.

Yeragani, V., Berger, R., Pohl, R., \& Balon, R. (2005). Effect of age on diurnal changes of 24-hour QT Interval variability. Pediatric Cardiology, 26(1), 39-44. 


\section{VITA}

Shirleatha Lee was born in 1979 in Memphis, TN, and graduated from East High School. Following completion of high school she enrolled at The University of Tennessee Martin in Martin, TN and later graduated with a Bachelor in Science in Nursing in 2002. While practicing on a Medical/Surgical Telemetry Unit she enrolled in graduate school at Union University and graduated with a Masters of Science in Nursing Education with honors. In August 2005, she assumed the role of Clinical Assistant Professor at the University of Memphis and began instructing within the undergraduatenursing program at the Loewenberg School of Nursing. In 2006 she was accepted to The University of Tennessee Health Science Center Memphis, TN to pursue a Doctor of Philosophy in Nursing. During her enrollment she was inducted as a Southern Regional Education Board Doctoral Scholar, received the Tennessee Promise of Nursing Faculty Award, The Department of Health and Human Services Faculty Award, and received a Dissertation Grant from Sigma Theta Tau International Beta Theta Chapter at-large. In addition she has presented research locally and regionally at Summer Nursing Residency Healthcare Conference, Sigma Theta Tau International Honor Society of Nursing Evidence Based Practice Conference, Southern Regional Network of Minority Research Investigators, Tennessee Nurses Association Annual Convention, Southern Nursing Research Society, and Mississippi Delta Healthcare Conference. 